\title{
Geologia, petrografia e geoquímica da associação tonalito-trondhjemito-granodiorito (TTG) do extremo leste do Subdomínio de Transição, Província Carajás, Pará \\ Geology, petrography and geochemistry of the association trondhjemite-tonalite-granodiorite (TTG) of the eastern end of the Transition Subdomain, Carajás Province, Pará
}

\author{
Patrick Araujo dos Santos', Mayara Fraeda Barbosa Teixeira', Roberto Dall'Agnol', Fabriciana Vieira Guimarães' \\ 'Universidade Federal do Pará. Belém, Pará, Brasil
}

\begin{abstract}
Resumo: O extremo leste do Subdomínio de Transição da Província Carajás é dominado por associação formada essencialmente por tonalitos e trondjhemitos com granodioritos subordinados (TTG), todos apresentando biotita e epidoto magmático como principais minerais máficos. Os tonalitos e trondhjemitos apresentam similaridades geoquímicas com suítes TTG arqueanas, enquanto os granodioritos seguem um trend cálcio-alcalino e apresentam enriquecimento em $\mathrm{K}_{2} \mathrm{O}, \mathrm{Rb}$ e $\mathrm{Ba}$, quando comparados com os trondhjemitos dominantes. Os dados geoquímicos não indicam uma vinculaçãa entre esses dois grupos de rochas, não havendo evidências de que os granodioritos derivem dos trondhjemitos por processos de cristalização fracionada ou fusão parcial de rochas TTG. Os tonalitos e trondhjemitos exibem afinidades com TTG de alta razão La/Yb e Sr/Y da Província Carajás, sugerindo que foram derivados de fontes à base de granada anfibolitos em altas pressões (cerca de 1,5 GPa) e tiveram sua evolução magmática controlada pelo fracionamento de granada e, possivelmente, anfibólio. A ampla distribuição da associação TTG na área estudada implica a existência expressiva de rochas tipo TTG no Subdomínio de Transição, o que pode fortalecer a hipótese de que o Subdomínio de Transição represente uma extensão do Domínio Rio Maria, mas afetado por eventos de retrabalhamento crustal neoarqueanos.
\end{abstract}

Palavras-chave: Trondhjemito. Granodiorito. TTG. Arqueano. Subdomínio de Transição.

Abstract: A tonalite-trondhjemite-granodiorite (TTG) suite is the main unit of the easternmost area of the Transition Subdomain of the Carajás Province. Trondhjemites and tonalites are dominants, with subordinate granodiorites, all containing biotite and magmatic epidote as main mafic minerals. The trondhjemites and tonalites show petrographic and geochemical characteristics similar to that of Archean TTG suites, while the granodiorites displays a calc-alkaline trend and are enriched in $\mathrm{K}_{2} \mathrm{O}, \mathrm{Rb}$ and $\mathrm{Ba}$, when compared to the dominant trondhjemites. The geochemical data apparently rule out a link between trondhjemites and granodiorites by fractional crystallisation or partial melting of the TTG. The tonalites and trondhjemites have affinities with TTG with high La/Yb and $\mathrm{Sr} / Y$ ratios of the Carajás province. This suggests a garnet amphibolite source, formation of the magma at high pressure (ca. $1.5 \mathrm{GPa}$ ) and magmatic evolution controlled by the fractionation of garnet and possibly amphibole. Plagioclase was probably absent in the source and was not a relevant fractionating phase. The wide occurrence of TTG in the mapped area indicates that these rocks are abundant in the Transition Subdomain, reinforcing the hypothesis that this region may represent an extension of the Rio Maria domain reworked during the Neoarchean.

Keywords: Trondhjemite. Granodiorite. TTG. Archean. Transition Subdomain.

SANTOS, P. A., M. F. B. TEIXEIRA, R. DALL'AGNOL \& F. V. GUIMARÃES, 2013. Geologia, petrografia e geoquímica da associação tonalitotrondhjemito-granodiorito (TTG) do extremo leste do Subdomínio de Transição, Província Carajás, Pará. Boletim do Museu Paraense Emílio Goeldi. Ciências Naturais 8(3): 257-290.

Autor para correspondência: Patrick Araujo dos Santos. Universidade Federal do Pará. Instituto de Geociências. Rua Augusto Corrêa, 1 Guamá. Belém, PA, Brasil. Caixa Postal 8608. CEP 66075-900 (patrick.santos86@gmail.com).

Recebido em 24/05/2013

Aprovado em 26/11/2013

Responsabilidade editorial: Fernando Jacques Althoff

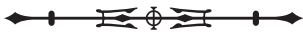




\section{INTRODUÇÃO}

O Subdomínio de Transição (Feio et al., 2013), porção sul do Domínio Carajás (Vasquez et al., 2008a), corresponde a uma faixa que se estende na direção E-W compreendida entre as cidades de Sapucaia e Canaã dos Carajás, dominada por granitoides arqueanos indiferenciados (Complexo Xingu; Silva et al., 1974; Vasquez et al., 2008a) e associações máficas a félsicas de rochas com hiperstênio interpretadas ora como granulitos, ora como charnockitos (Complexo Pium; Pidgeon et al., 2000; Ricci \& Carvalho, 2006; Vasquez et al., 2008a; Galarza et al., 2012) e corpos graníticos da Suíte Plaquê. Com o avanço do conhecimento, o quadro estratigráfico desse subdomínio vem sendo progressivamente melhor definido (D. C. Oliveira et al., 2010; Feio et al., 2013; E. O. Gabriel \& D. C. Oliveira, comunicação pessoal, 2013; A. C. Silva, R. Dall'Agnol, F. V. Guimarães \& D. C. Oliveira, comunicação pessoal, 2013) e novas unidades granitoides arqueanas estão sendo gradualmente individualizadas, tendendo a substituir o Complexo Xingu nessa região. Os dados atualmente disponíveis na literatura relatam uma ocorrência variada de granitoides arqueanos nesse subdomínio, cujas idades, origem e evolução devem ser esclarecidas de modo a permitir sua comparação com os granitoides já caracterizados em outras porções da Província Carajás. Por outro lado, o significado tectônico do Subdomínio de Transição (SDT) permanece controverso, pois pode corresponder a uma extensão do Domínio Rio Maria retrabalhada intensamente durante os eventos neoarqueanos que afetaram a Bacia Carajás, ao norte (Dall'Agnol et al., 2006), ou representar um bloco tectônico distinto daquele do Domínio Rio Maria, como sugerem os dados recentemente obtidos na área de Canaã dos Carajás, no extremo norte do SDT (Feio et al., 2013). Desse modo, uma melhor compreensão da evolução do SDT é fundamental para o entendimento da compartimentação e evolução da Província Carajás.

Estudos efetuados nas proximidades de Sapucaia, no extremo leste do SDT, revelaram uma predominância de associações tonalito-trondhjemito-granodiorito (TTG) com características compatíveis com as típicas suítes TTG arqueanas (Moyen \& Martin, 2012). Até o desenvolvimento do presente trabalho, essa associação TTG não havia sido devidamente caracterizada e era inteiramente desprovida de estudos de detalhe, apesar de sua grande relevância para a compreensão da evolução geológica do Subdomínio de Transição. As informações de campo, juntamente com estudos petrográficos e geoquímicos, proporcionaram avanços expressivos no conhecimento dessas rochas. Tais dados são apresentados e discutidos neste artigo e permitiram, ainda, comparálas com associações granitoides similares já estudadas na Província Carajás, bem como com as novas unidades granitoides arqueanas que estão sendo gradualmente individualizadas no SDT. Este trabalho representa uma contribuição para os avanços na compreensão das associações TTG e da evolução magmática e tectônica do Subdomínio de Transição e de suas relações com os demais domínios da Província Carajás.

\section{CONTEXTO GEOLÓGICO REGIONAL}

A Província Carajás (Figura 1A) integra a porção suloriental da Província Amazônia Central (Tassinari \& Macambira, 2004), no sudeste do Cráton Amazônico. Compreende basicamente dois domínios distintos, assumidos no recente mapa geológico do estado do Pará (Vasquez et al., 2008a). Ao sul há o Domínio Rio Maria, de idade mesoarqueana, constituído por greenstone belts (Supergrupo Andorinhas), suítes TTG, formadas entre 2,98 e 2,86 Ga (Tonalito Arco Verde, Trondhjemito Mogno, Complexo Tonalítico Caracol, Tonalito Mariazinha e Trondhjemito Água Fria), granitoides com alto Mg, dominantemente granodioríticos, com idade de 2,87 Ga (Granodiorito Rio Maria e demais rochas de afinidade sanukitoide englobadas na Suíte Rio Maria), leucogranodioritos e leucomonzogranitos cálcio-alcalinos, também formados em 2,87 Ga (Suíte Guarantã e granitos correlatos), e pelos leucogranitos 
potássicos, de 2,86 Ga, representados pelos granitos Xingara, Mata Surrão e similares (Pimentel \& Machado, 1994; Macambira \& Lafon, 1995; Leite \& Dall'Agnol, 1997; Dall'Agnol et al., 2006; Oliveira et al., 2009; Almeida et al., 2010, 2011; Guimarães et al., 2010; M. A. Oliveira et al., 2010). Ao norte há o Domínio Carajás, subdividido em dois subdomínios distintos (Dall'Agnol et al., 2006): (1) a Bacia Carajás, tendo por provável embasamento gnaisses quartzo-feldspáticos do Complexo Xingu e sendo formada essencialmente por sequências metavulcano-sedimentares do Supergrupo Itacaiúnas (2,76 Ga; Machado et al., 1991), seccionadas por granitoides subalcalinos de 2,76 a 2,56 Ga (Complexo Granítico Estrela, granitos Serra do Rabo, Igarapé Gelado e Old Salobo; Machado et al., 1991; Huhn et al., 1999; Sardinha et al., 2006; Barros et al., 2009); (2) o Subdomínio de Transição (Figura 1B), composto pelo Ortogranulito Chicrim-Cateté (Vasquez et al., 2008b), Tonalito Bacaba ( 3,0 Ga, Moreto et al., 2011), granitoides e gnaisses indiferenciados do Complexo Xingu (2,97 a 2,86 Ga; Machado et al., 1991; Avelar et al., 1999), Diopsídio-Norito Pium, com idade e origem, se magmática ou metamórfica, ainda controversas (Hirata et al., 1982; 3,0-2,85 Ga; Pidgeon et al., 2000; Santos et al., 2008; ca. 2,75-2,73 Ga, Galarza et al., 2012), Suíte Intrusiva Cateté (Macambira \& Vale, 1997), com idades de 2,76 Ga (Lafon et al., 2000), Suíte Pedra Branca ( 2,75 Ga; Sardinha et al., 2004; Gomes \& Dall'Agnol, 2007; Feio et al., 2013) e os plútons das suítes Plaquê e Planalto, com idades entre 2,74 e 2,72 Ga (Avelar et al., 1999; Huhn et al., 1999; Sardinha et al., 2004; Vasquez et al., 2008a; Feio et al., 2012, 2013).

Em estudos mais detalhados na porção norte do SDT, Feio et al. (2013) individualizaram rochas granitoides mesoarqueanas, representadas pelo Granito Canaã dos Carajás (2,96 Ga), Trondjhemito Rio Verde (2,87-2,85 Ga), Complexo Tonalítico Campina Verde (2,87 a 2,85 Ga), e granitos Bom Jesus (3,0 a 2,83
Ga), Cruzadão (2,85 Ga) e Serra Dourada (2,83 Ga). Do mesmo modo, Silva et al. (comunicação pessoal, 2013) discriminaram na porção centro-sul do SDT, imediatamente a oeste da área estudada, rochas tonalíticas com idade de 2,94 Ga (Guimarães, comunicação pessoal, 2013), denominadas de Tonalito São Carlos, além de uma associação TTG com idade de 2,87 Ga, que recebeu a designação de Trondhjemito Colorado (Silva et al., 2010), e diversos tonalitos e granodioritos agrupados na associação granitoide Vila Jussara, com idades entre 2,75 e 2,72 Ga (Guimarães, comunicação pessoal, 2013; D. C. Oliveira et al., 2010).

Um pouco mais a oeste, ainda em área do SDT, Gabriel \& Oliveira (comunicação pessoal, 2013) identificaram granodioritos de alto $\mathrm{Mg}$, denominados de Água Limpa e Água Azul, ambos intensamente deformados e com idade de $\sim 2,87 \mathrm{Ga}$.

\section{ASSOCIAÇÕES TTG DA PROVÍNCIA CARAJÁS}

Os granitoides das associações TTG (Moyen \& Martin, 2012) possuem ampla distribuição na Província Carajás. No Domínio Carajás, especificamente no SDT, o Trondhjemito Rio Verde (Feio et al., 2013) e o Tonalito Colorado (Silva et al., comunicação pessoal, 2013) foram reconhecidos como unidades similares às típicas associações TTG. O Trondhjemito Rio Verde ( 2,87 a 2,85 Ga; Feio et al., 2013) foi identificado apenas na área de Canaã dos Carajás, na porção norte do Subdomínio de Transição. São trondhjemitos com textura granular hipidiomórfica, variando para rochas bandadas, com alternância de níveis trondhjemíticos e tonalíticos. Em termos geoquímicos, exibem altas razões La/Yb e ausência de anomalias de Eu. $\bigcirc$ Trondhjemito Colorado ( 2,87 Ma; Silva et al., 2010) ocorre nas proximidades de Vila Jussara, centro-sul do Subdomínio de Transição. Mostra composições dominantemente trondhjemíticas, com granodioritos subordinados. São rochas bandadas, intensamente deformadas, comumente englobando enclaves máficos. Suas características geoquímicas são 
compatíveis com aquelas dos TTG arqueanos (Silva et al., comunicação pessoal, 2013).

Na porção sul da Província, no Domínio Rio Maria (DRM), as associações TTG possuem ampla distribuição e são representadas por Tonalito Arco Verde, Trondhjemito Mogno, Complexo Tonalítico Caracol, Tonalito Mariazinha e Trondhjemito Água Fria (Althoff et al., 2000; Leite et al., 2004; Dall'Agnol et al., 2006; Guimarães et al., 2010). As rochas dessas unidades podem apresentar bandamento composicional e estão deformadas, mas ainda exibem texturas ígneas bem preservadas. Geralmente englobam enclaves máficos ou quartzo-dioríticos e mostram estruturação segundo o trend regional NW-SE, com exceção do Tonalito Mariazinha, orientado dominantemente em direções NE-SW a N-S, discordantes do trend regional.

Todas essas unidades são formadas por biotitatonalitos e trondhjemitos, com raros granodioritos associados. Apenas no Trondhjemito Água Fria temse maior proporção de granodioritos. Em estudos recentes, Almeida et al. (2011) refinaram a caracterização dessas rochas, distinguindo pelo menos três eventos magmáticos de composição TTG no DRM. O primeiro evento é representado pelo Trondhjemito Mogno, juntamente com as rochas mais antigas do Tonalito Arco Verde, com idades de 2,96 \pm 0,2 Ga. O Complexo Tonalítico Caracol, Tonalito Mariazinha e as rochas mais jovens do Tonalito Arco Verde constituem a segunda geração, com idades de 2,93 \pm 0,2 Ga. $O$ último período de magmatismo TTG registrado nesse domínio é datado em 2,86 \pm 0,1 Ga e engloba as rochas do Trondhjemito Água Fria. Os mesmos autores agruparam as suítes TTG do Domínio Rio Maria em três grupos geoquímicos, os quais não apresentam relação direta com os três episódios de geração de magmas mencionados, pois as diferentes unidades TTG apresentam rochas em vários grupos: (1) grupo com altas razões La/Yb, Sr/Y e Nb/Ta, que concentra rochas do Trondhjemito Mogno e Tonalito Mariazinha; (2) grupo com moderadas razões La/Yb, que reúne grande parte do Complexo Tonalítico Caracol e Trondhjemito Água Fria, mas também engloba rochas das demais unidades; e (3) grupo com baixas razões La/Yb, Sr/Y e Nb/Ta, onde dominam as rochas do Tonalito Arco Verde.

\section{GEOLOGIA DO EXTREMO LESTE DO SUBDOMÍNIO DE TRANSIÇÃO}

O mapeamento geológico na escala 1:50.000 no extremo leste do Subdomínio de Transição (Figura 1C), no entorno do município de Sapucaia, sudeste do Pará, demonstrou que a área estudada é dominada por rochas da associação tonalito-trondhjemito-granodiorito (TTG). De modo subordinado, foram identificadas rochas metaultramáficas correlacionadas ao greenstone de Sapucaia e tonalitos portadores de anfibólios, distintos dos TTG dominantes e similares ao Tonalito São Carlos, descrito originalmente a oeste (Silva et al., comunicação pessoal, 2013). No centro-sul da área, destaca-se uma pequena serra de morfologia saliente no relevo local, alongada na direção E-W, dominada por leucogranodioritos porfiríticos (Teixeira et al., 2013). Próximo ao limite com o Cinturão Araguaia (extremo leste do SDT), aflora um pequeno corpo deformado, alongado segundo E-W (concordante com o padrão regional), de composição monzogranítica, correlacionado com base em suas características geoquímicas aos granitos da Suíte Planalto. Na porção norte da área há, ainda, um conjunto de tonalitos e granodioritos similares aos descritos na associação granitoide Vila Jussara (Guimarães, comunicação pessoal, 2013) e gabros correlacionados ao Complexo Pium (Teixeira, comunicação pessoal, 2013). Um corpo de granitos isotrópicos, similares aos granitos anorogênicos paleoproterozoicos, e diversos diques máficos desprovidos de deformação expressiva seccionam os litotipos arqueanos mapeados. O presente trabalho atém-se à associação TTG identificada e não efetuará abordagem mais profunda dos demais granitoides mapeados. 







\section{PRINCIPAIS ASPECTOS GEOLÓGICOS DA ASSOCIAÇÃO TTG}

A associação TTG aflora na forma de blocos ou lajedos (Figura 2A), geralmente em áreas de relevo arrasado, com respostas radiométricas muito baixas (3,3-5,2 $\mu R / h)$, ocupando áreas de anomalias negativas em mapas aerorradiométricos. Nessa associação dominam rochas tonalíticas/trondhjemíticas. Os granodioritos ocorrem em pequeno volume, entremeados aos tonalitos/ trondhjemitos e não formam corpos mapeáveis na área estudada. As suas relações de contato com os demais litotipos identificados não foram observadas no campo. São rochas de cor cinza e granulação média, mostrando bandamento composicional ou, mais raramente, textura granular. Frequentemente, englobam enclaves quartzodioríticos ou anfibolíticos, alongados segundo a foliação da rocha ou tentando amoldar-se à estruturação existente (Figura 2B). Por vezes, as extremidades dos enclaves são interpenetradas na rocha encaixante, em um aspecto de assimilação, sugerindo baixo contraste de viscosidade entre os enclaves e a encaixante. Em algumas ocorrências, foram observadas intercalações de rochas trondhjemíticas e graníticas, evidenciando injeções de líquidos graníticos ao longo dos planos de foliação, cuja origem necessita ser investigada em estudos de maior detalhe.

De modo geral, essas rochas se apresentam intensamente deformadas, estruturadas segundo a direção NW-SE a E-W (Figura 2G), com mergulhos fortemente inclinados a verticais. A foliação, marcada pelo bandamento composicional, é a principal feição estrutural. Por vezes, elas apresentam dobramentos (Figura 2C), com eixos na direção NW-SE, e comumente possuem associados veios leucograníticos, afetados pela mesma deformação (Figura 2D). Esta é responsável por dobramentos nos veios e nos bandamentos composicionais dos TTG e se desenvolveu em condições dúcteis. Localmente, apresentam foliação NE-SW afetada por cisalhamento E-W, que causa transposição (Figura 2E). A transposição inicia com um leve dobramento do bandamento e veios associados; com o aumento da deformação, as dobras ficam mais apertadas, gerando uma foliação de plano axial, paralela à foliação regional; por fim, as charneiras das dobras são rompidas, dando lugar a um bandamento E-W.

Diferentes locais da área estudada se encontram afetados por zonas de cisalhamento, caracterizadas por apresentarem rochas com foliações miloníticas e lineação de estiramento mineral. A foliação possui direção preferencial N70E, com mergulhos de $65^{\circ}$ para SE. A lineação é quase horizontal, com mergulhos em torno de $5^{\circ}$ para S70W. A deformação milonítica é revelada principalmente pelas formas ovaladas dos porfiroclastos assimétricos rotacionados de feldspatos (Afloramento PFA52; Figura 2F), contornados por ribbons de quartzo e níveis de biotita, bem como por foliações tipo S/C e por veios leucograníticos boudinados. A relação observada entre a foliação milonítica e lineação mineral, somada aos critérios cinemáticos oferecidos pelos cristais ocelares de feldspatos com sombra de pressão, indica um movimento oblíquo de baixo ângulo, com esforço dominante em direção NNESSW e deslocamento de massa para oeste.

Após a instalação de zonas de cisalhamento dúctil, essa região foi submetida a esforços rúpteis de direção preferencial NE-SW, registrados principalmente na ocorrência de um grande lineamento estrutural, marcado em campo por zonas silicificadas, que seccionam o leste do Subdomínio de Transição, além de diques máficos, e uma segunda geração de veios leucograníticos não deformados, que também cortam as rochas arqueanas na mesma direção. Essa fase estrutural provocou o fraturamento das rochas aflorantes e, eventualmente, falhamento de rejeito direcional decimétrico.

\section{PETROGRAFIA}

\section{COMPOSIÇÕES MODAIS E CLASSIFICAÇÃO}

A associação TTG estudada é formada por rochas de cor cinza, com textura granular média e feições anisotrópicas. 


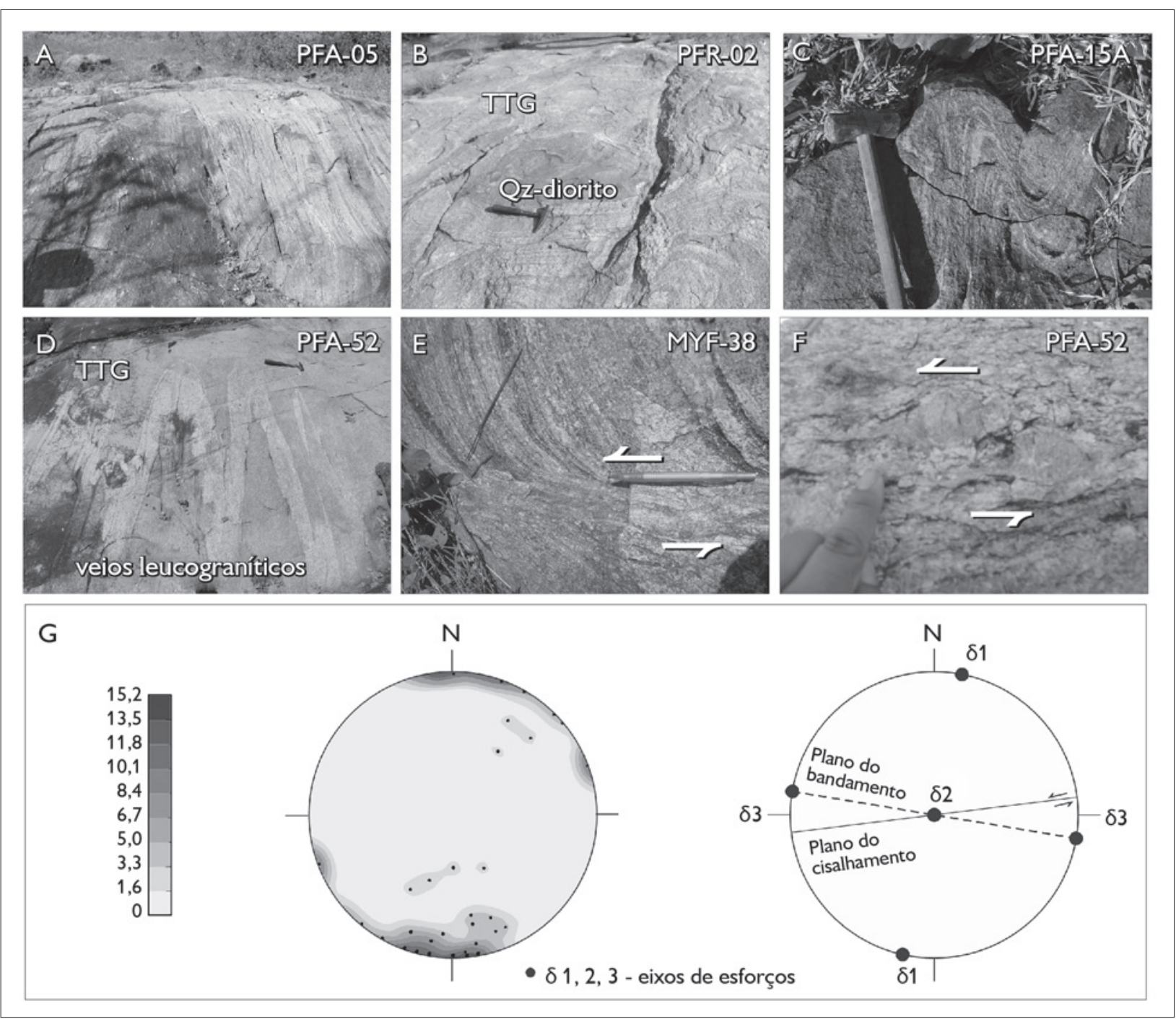

Figura 2. Aspectos de campo da associação TTG da porção extremo leste do Subdomínio de Transição. A) Bandamento composicional; B) enclave quartzo-diorítico; C) bandamento dobrado; D) veios leucograníticos dobrados; E) cisalhamento E-W causando a transposição da foliação NE-SW preexistente; F) porfiroclastos ocelares de feldspato rotacionados; G) diagramas de polos de foliação juntamente com a orientação dos eixos de esforços para as rochas estudadas (Rede de Schmit-Lambert, hemisfério inferior).

A Tabela 1 apresenta as composições modais em percentagem em volume obtidas para essas rochas. Os diagramas Q-A-P e Q-A+P-M' apontaram composições dominantemente trondhjemíticas a tonalíticas, com granodioritos subordinados (Figura 3).

A classificação petrográfica da maioria das rochas estudadas, feita com base na composição modal, mostrou equivalência com os dados geoquímicos, excetuando as amostras PFR-1, PFR-10A, PFR-24, MYF-1 e MYF-48B, que foram classificadas como trondhiemitos nos estudos petrográficos e apresentam composições químicas que levam a classificá-las como granodioritos (ver adiante).

De modo geral, as amostras analisadas são formadas essencialmente por plagioclásio e quartzo, com proporções modais variáveis de $51 \%$ a $70,6 \%$ e $15,5 \%$ a $36,0 \%$ e médias de 66,0\% e 25,2\%, respectivamente (Tabela 1).

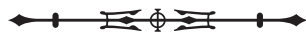




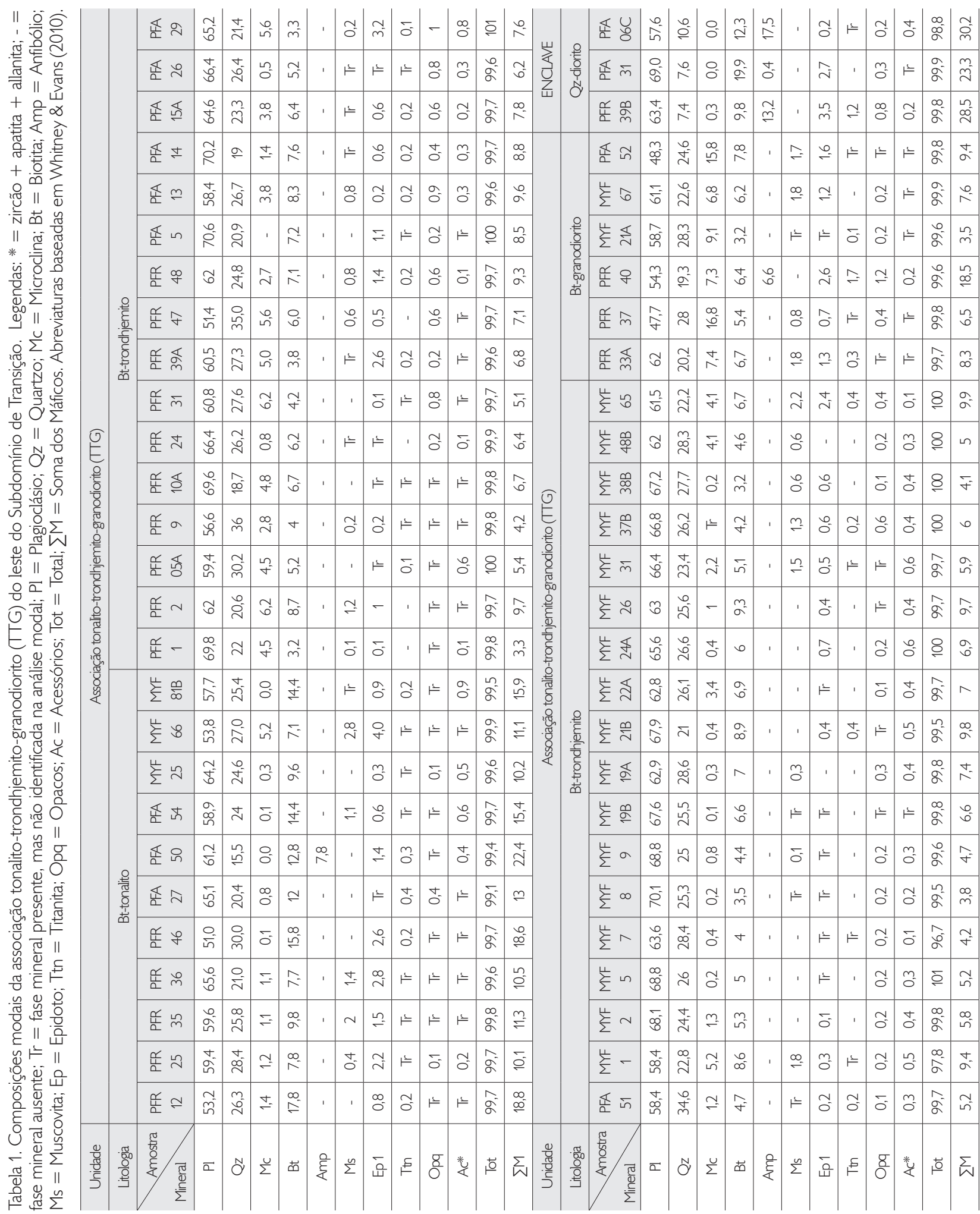



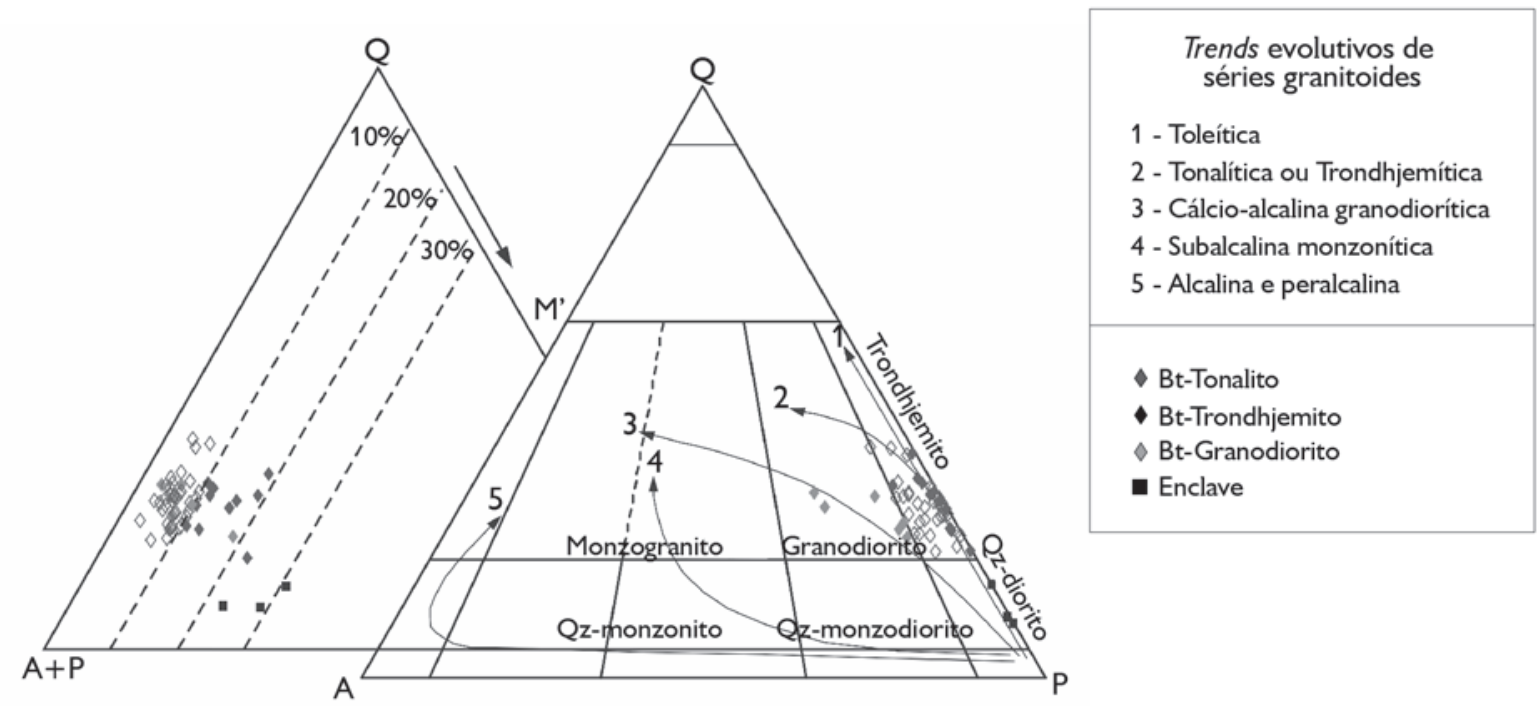

Figura 3. Diagramas Q-A-P e Q-A+P-M' (Streckeisen, 1976) para a associação tonalito-trondhjemito-granodiorito do leste do Subdomínio de Transição. Os números de 1 a 5 são trends evolutivos de séries granitoides (Lameyre \& Bowden, 1982; Bowden et al., 1984).

A microclina é um constituinte acessório nos trondhjemitos e tonalitos $(0,1 \%$ a $6,2 \%)$, passando a ser significativa nas variedades granodioríticas (6,8\% a 16,8\%). A biotita é a principal fase máfica (média de 7\%) e o anfibólio está presente em apenas duas amostras (PFR-40 e PFA-50). Minerais opacos, epidoto, muscovita, allanita, apatita, titanita e zircão (em conjunto, com média de 1,9\%) constituem as principais fases acessórias. Os enclaves mostram composições quartzo-dioríticas.

\section{ASPECTOS MINERALÓGICOS E TEXTURAIS}

As variedades petrográficas identificadas possuem aspectos mineralógicos e texturais similares, motivo pelo qual serão tratadas conjuntamente. Apresentam trama ígnea pouco preservada, mascarada por intensa recristalização. Comumente exibem porfiroclastos ovalados de plagioclásio, imersos em uma matriz granular fina $(<1 \mathrm{~mm})$ a muito fina $(<0,1 \mathrm{~mm})$ proveniente da cominuição e recristalização de cristais primitivos (Figura 4A). Por vezes, mostram o desenvolvimento de foliação milonítica, com arranjo granolepidoblástico (Figura 4B).
O plagioclásio é o principal constituinte dessas rochas e ocorre em três diferentes tipos texturais: o plagioclásio 1 é relativamente raro e forma cristais subédricos de granulação média, por vezes dispostos em agregados que sugerem relações de synneusis (Vance, 1969). Exibe alteração mais intensa no núcleo dos cristais, indicando a presença de zoneamento normal (Figura 4C). Esses cristais são admitidos como fases magmáticas, pouco afetadas pelos processos de recristalização dominante nessas rochas. O plagioclásio 2 se apresenta como porfiroclastos subarredondados ou ocelares de granulação média, envoltos por uma matriz microcristalina recristalizada. Apresenta maclas pouco marcantes e cristais com aspecto límpido, evidenciando ausência de alteração. O plagioclásio 3 forma cristais finos a muito finos, dispostos em agregados de grãos com contatos retos ou poligonais entre si e com os demais minerais da trama. Mostram extinção ondulante e podem ou não apresentar maclamentos. Comumente, constituem texturas em mosaico na matriz das rochas que evidenciam processos intensos de recristalização em condições estáticas.






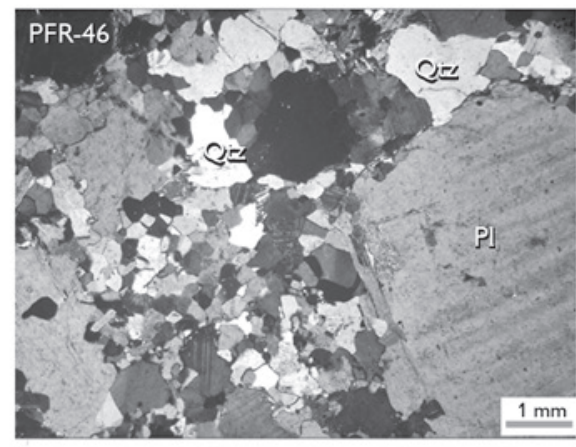

A


$E$

G

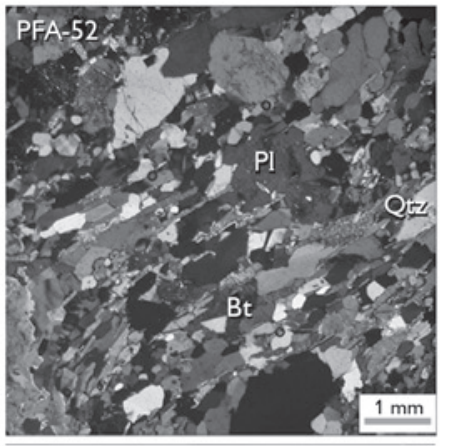

B
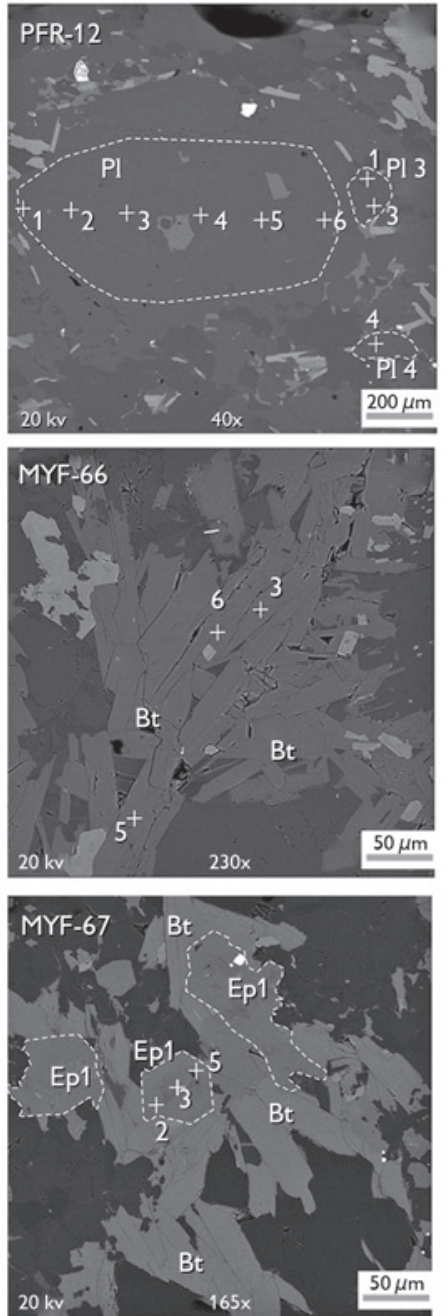

Figura 4. Aspectos mineralógicos e texturais das rochas estudadas. A) Porfiroclastos ovalados de plagioclásio imersos em matriz granular fina; B) foliação milonítica, marcada por lamelas de biotita em arranjo granolepidoblástico; C) cristal subédrico de plagioclásio com indícios de zoneamento normal; D) imagem de Microscopia Eletrônica de Varredura (MEV) dos plagioclásios tipo 1 e 3 mostrando os pontos analisados por Energy Dispersive Spectroscopy (EDS) (válido também para as Figuras Fe H); E) agregados de biotita; F) imagem de MEV de biotitas; G) associação textural de cristais de epidoto automorfos e parcialmente corroídos e biotita; H) imagem de MEV de Epidoto tipo 1 associado com biotita. Simbologia: Kretz (1983). 
Análises semiquantitativas por Energy Dispersive Spectroscopy (EDS) efetuadas em microscópio eletrônico de varredura (Tabela 2; Figura 4D) revelaram que os plagioclásios analisados possuem composição de oligoclásio cálcico $\left(\mathrm{An}_{27-19}\right.$; Figura 5A), com teores de Or variando de 0,68\% a 2,2\%. Foram observadas variações composicionais consideráveis entre borda e núcleo de um mesmo cristal (plagioclásio 1), indicando a presença de zoneamento normal. Os cristais finos neoformados de plagioclásio (plagioclásio 3) presentes na matriz, ou desenvolvidos em torno dos fenocristais, possuem igualmente composição de oligoclásio $\left(\mathrm{An}_{22-17}\right.$;
Tabela 2), similar às das bordas dos cristais de plagioclásio 1 ou ligeiramente mais sódicas (Figura 5A).

quartzo é encontrado em cristais anédricos, inequigranulares, quase sempre recristalizados. Forma agregados policristalinos com contatos retos em junção tríplice, definindo texturas em mosaico. Geralmente definem cordões ou ribbons de grãos recristalizados alongados de acordo com a foliação da rocha, contornando porfiroclastos de plagioclásio em uma trama milonítica. As feições deformacionais mais frequentes são extinção ondulante, formação de subgrãos e novos grãos.

Tabela 2. Análises químicas semiquantitativas de plagioclásios da associação tonalito-trondhjemito-granodiorito (TTG) do leste do Subdomínio de Transição. Legendas: PL-1 = plagioclásio 1;PL-3 = plagioclásio3; $\mathrm{B}=$ borda; $\mathrm{N}=$ núcleo; $\mathrm{R}=$ recristalizado; $\mathrm{Bt}=$ biotita; FeO* $=$ Fetotal calculado como FeO .

\begin{tabular}{|c|c|c|c|c|c|c|c|c|c|c|c|c|c|c|c|c|c|c|}
\hline Litologia & \multicolumn{9}{|c|}{ Bt-tonalito } & \multicolumn{9}{|c|}{ Bt-granodiorito } \\
\hline Amostra & \multicolumn{9}{|c|}{ PFR-12 } & \multicolumn{9}{|c|}{ MYF-67 } \\
\hline Mineral & PL-1 & PL-1 & PL-1 & PL-1 & PL-1 & PL-1 & PL-3 & PL-3 & PL-3 & PL-1 & PL-1 & PL-1 & PL-1 & PL-1 & PL-1 & PL-3 & PL-3 & PL-3 \\
\hline Análise & C1-1 & $\mathrm{C} 1-2$ & $\mathrm{C} 1-3$ & C1-4 & C1-5 & C1-6 & C2-1 & $C 2-3$ & C2-4 & C1-1 & $\mathrm{C} 1-2$ & C1-3 & C1-4 & C1-5 & C1-6 & C22-3 & C $32-3$ & C $32-5$ \\
\hline & B & B & B & $N$ & $N$ & B & $\mathrm{R}$ & $\mathrm{R}$ & $\mathrm{R}$ & B & B & $N$ & $N$ & B & B & $\mathrm{R}$ & $\mathrm{R}$ & $\mathrm{R}$ \\
\hline $\mathrm{SiO}_{2}$ & 68,73 & 67,26 & 67,01 & 67,29 & 66,90 & 68,48 & 68,29 & 68,81 & 67,75 & 69,10 & 68,51 & 66,96 & 67,90 & 67,18 & 69,88 & 69,57 & 69,99 & 69,43 \\
\hline $\mathrm{Al}_{2} \mathrm{O}_{3}$ & 24,77 & 25,02 & 25,07 & 25,45 & 25,29 & 24,55 & 24,46 & 24,40 & 23,80 & 24,30 & 24,80 & 26,35 & 25,54 & 25,19 & 24,31 & 24,29 & 24,51 & 24,30 \\
\hline $\mathrm{FeO} *$ & 0,06 & 0,14 & 0,15 & 0,17 & 0,12 & 0,12 & 0,15 & 0,23 & 0,08 & 0,21 & 0,14 & 0,12 & 0,17 & 0,12 & 0,08 & 0,11 & 0,15 & 0,10 \\
\hline $\mathrm{CaO}$ & 4,53 & 5,01 & 5,18 & 5,10 & 5,50 & 4,61 & 4,15 & 4,15 & 3,57 & 4,04 & 4,61 & 6,22 & 5,17 & 4,72 & 3,99 & 4,03 & 4,07 & 4,54 \\
\hline $\mathrm{Na}_{2} \mathrm{O}$ & 8,49 & 8,03 & 8,08 & 7,85 & 7,78 & 8,47 & 8,63 & 8,35 & 8,93 & 8,75 & 8,35 & 7,32 & 8,08 & 8,16 & 8,52 & 8,69 & 8,37 & 8,33 \\
\hline $\mathrm{K}_{2} \mathrm{O}$ & 0,26 & 0,32 & 0,30 & 0,29 & 0,30 & 0,39 & 0,14 & 0,11 & 0,22 & 0,12 & 0,24 & 0,12 & 0,12 & 0,13 & 0,16 & 0,21 & 0,19 & 0,21 \\
\hline Total & 106,8 & 105,8 & 105,8 & 106,2 & 105,9 & 106,6 & 105,8 & 106,0 & 104,3 & 106,5 & 106,6 & 107,1 & 107,0 & 105,5 & 106,9 & 106,9 & 107,3 & 106,9 \\
\hline \multicolumn{19}{|c|}{ Fórmula química calculada à base de 32 oxigênios } \\
\hline $\mathrm{Si}$ & 11,31 & 11,20 & 11,17 & 11,16 & 11,14 & 11,31 & 11,33 & 11,38 & 11,40 & 11,39 & 11,29 & 11,02 & 11,17 & 11,20 & 11,44 & 11,42 & 11,43 & 11,40 \\
\hline $\mathrm{Al}$ & 4,80 & 4,91 & 4,93 & 4,98 & 4,96 & 4,78 & 4,79 & 4,76 & 4,72 & 4,72 & 4,82 & 5,11 & 4,95 & 4,95 & 4,69 & 4,70 & 4,72 & 4,70 \\
\hline $\mathrm{Fe}$ & 0,01 & 0,02 & 0,02 & 0,02 & 0,02 & 0,02 & 0,02 & 0,03 & 0,01 & 0,03 & 0,02 & 0,02 & 0,02 & 0,02 & 0,01 & 0,02 & 0,02 & 0,01 \\
\hline $\mathrm{Ca}$ & 0,79 & 0,88 & 0,91 & 0,89 & 0,97 & 0,80 & 0,73 & 0,73 & 0,63 & 0,70 & 0,80 & 1,08 & 0,90 & 0,83 & 0,69 & 0,70 & 0,70 & 0,79 \\
\hline $\mathrm{Na}$ & 2,71 & 2,59 & 2,61 & 2,53 & 2,51 & 2,71 & 2,78 & 2,68 & 2,91 & 2,80 & 2,67 & 2,34 & 2,58 & 2,64 & 2,70 & 2,77 & 2,65 & 2,65 \\
\hline K & 0,05 & 0,07 & 0,06 & 0,06 & 0,06 & 0,08 & 0,03 & 0,02 & 0,05 & 0,02 & 0,05 & 0,02 & 0,03 & 0,03 & 0,03 & 0,04 & 0,04 & 0,04 \\
\hline Cátions & 19,67 & 19,67 & 19,70 & 19,64 & 19,67 & 19,70 & 19,68 & 19,59 & 19,72 & 19,66 & 19,66 & 19,60 & 19,65 & 19,66 & 19,58 & 19,64 & 19,56 & 19,60 \\
\hline Sítio T & 16,12 & 16,13 & 16,12 & 16,16 & 16,12 & 16,10 & 16,14 & 16,17 & 16,13 & 16,14 & 16,13 & 16,15 & 16,15 & 16,16 & 16,15 & 16,13 & 16,17 & 16,11 \\
\hline Sítio M & 3,55 & 3,54 & 3,59 & 3,48 & 3,55 & 3,60 & 3,54 & 3,43 & 3,59 & 3,52 & 3,52 & 3,45 & 3,50 & 3,50 & 3,43 & 3,51 & 3,39 & 3,48 \\
\hline Anortita & 22,19 & 24,93 & 25,45 & 25,69 & 27,31 & 22,36 & 20,63 & 21,18 & 17,66 & 19,97 & 22,82 & 31,43 & 25,71 & 23,78 & 20,17 & 19,94 & 20,72 & 22,65 \\
\hline Albita & 76,27 & 73,16 & 72,80 & 72,52 & 70,88 & 75,38 & 78,51 & 78,14 & 81,05 & 79,34 & 75,77 & 67,85 & 73,56 & 75,40 & 78,88 & 78,79 & 78,11 & 76,11 \\
\hline Ortoclásio & 1,54 & 1,91 & 1,76 & 1,79 & 1,82 & 2,26 & 0,87 & 0,68 & 1,29 & 0,69 & 1,42 & 0,72 & 0,74 & 0,81 & 0,95 & 1,26 & 1,17 & 1,24 \\
\hline
\end{tabular}




A microclina aparece sempre na matriz em raros cristais finos a muito finos anédricos, geralmente intersticiais, exibindo límpido maclamento albita-periclina. Nas variedades granodioríticas, são de ocorrência mais expressiva e podem formar cristais de granulação média subarredondados, incipientemente pertíticos, bordejados por matriz félsica recristalizada.

A biotita forma lamelas subédricas (Figura 4E) de granulação fina a média, com pleocroísmo variando de castanho-pálido a marrom. Suas lamelas possuem orientação preferencial, definindo a foliação da rocha. Formam agregados com os demais minerais máficos e se associam comumente com muscovita e epidoto. Análises químicas semiquantitativas (Tabela 3), também obtidas por EDS em MEV (Figura 4F), apontaram composições de biotitas ferromagnesianas (Foster, 1960), com ligeira dominância de $\mathrm{Fe}$ sobre $\mathrm{Mg}(\mathrm{Fe} /[\mathrm{Fe}+\mathrm{Mg}]$ variando de 0,54 a 0,59). De acordo com os critérios de Nachit et al. (2005), suas composições se situam preferencialmente no campo de biotitas magmáticas primárias, passando para

Tabela 3. Análises químicas semiquantitativas de biotita da associação tonalito-trondhjemito-granodiorito (TTG) do leste do Subdomínio de Transição. Legenda: Bt = biotita.

\begin{tabular}{|c|c|c|c|c|c|c|c|c|c|c|c|c|}
\hline \multirow{3}{*}{$\begin{array}{c}\text { Litologia } \\
\text { Amostra } \\
\text { Mineral }\end{array}$} & \multicolumn{9}{|c|}{ Bt-tonalito } & \multirow{2}{*}{\multicolumn{3}{|c|}{$\begin{array}{c}\text { Bt-trondhjemito } \\
\text { PFA-14 }\end{array}$}} \\
\hline & \multicolumn{3}{|c|}{ PFR-12 } & \multicolumn{3}{|c|}{ MYF-66 } & \multicolumn{3}{|c|}{ PRF-36 } & & & \\
\hline & $\mathrm{Bt}$ & $\mathrm{Bt}$ & $\mathrm{Bt}$ & $\mathrm{Bt}$ & $\mathrm{Bt}$ & $\mathrm{Bt}$ & $\mathrm{Bt}$ & $\mathrm{Bt}$ & $\mathrm{Bt}$ & $\mathrm{Bt}$ & $\mathrm{Bt}$ & $\mathrm{Bt}$ \\
\hline Análise & C2-1 & C2-2 & $C 2-4$ & $C 1-3$ & C1-5 & C1-6 & C2-1 & C2-2 & $C 2-3$ & C2-1 & $C 2-3$ & C2-4 \\
\hline $\mathrm{SiO}_{2}$ & 40,59 & 41,47 & 40,74 & 40,11 & 41,27 & 40,21 & 40,88 & 40,42 & 39,82 & 40,02 & 40,03 & 39,98 \\
\hline $\mathrm{TiO}_{2}$ & 2,61 & 2,67 & 3,05 & 1,76 & 1,93 & 2,49 & 2,64 & 2,88 & 2,69 & 2,58 & 2,42 & 2,75 \\
\hline $\mathrm{Al}_{2} \mathrm{O}_{3}$ & 16,96 & 17,45 & 16,75 & 17,08 & 17,64 & 17,57 & 17,60 & 17,46 & 17,53 & 16,60 & 16,64 & 16,18 \\
\hline $\mathrm{FeO}$ & 20,11 & 18,14 & 19,88 & 21,73 & 20,50 & 21,31 & 20,35 & 21,09 & 20,24 & 20,12 & 20,36 & 20,20 \\
\hline $\mathrm{MgO}$ & 8,15 & 8,37 & 8,20 & 8,73 & 8,09 & 8,40 & 8,66 & 8,37 & 8,20 & 8,93 & 9,54 & 9,29 \\
\hline $\mathrm{MnO}$ & 0,56 & 0,48 & 0,38 & 0,49 & 0,70 & 0,53 & 0,46 & 0,26 & 0,41 & 0,56 & 0,33 & 0,60 \\
\hline $\mathrm{CaO}$ & 0,22 & 0,38 & 0,20 & 0,18 & 0,12 & 0,16 & 0,17 & 0,19 & 0,19 & 0,17 & 0,10 & 0,16 \\
\hline $\mathrm{K}_{2} \mathrm{O}$ & 10,45 & 9,63 & 10,07 & 10,48 & 9,84 & 10,51 & 10,44 & 10,62 & 10,07 & 10,06 & 10,15 & 10,13 \\
\hline Total & 99,6 & 98,6 & 99,3 & 100,6 & 100,1 & 101,2 & 101,2 & 101,3 & 99,2 & 99,0 & 99,6 & 99,3 \\
\hline \multicolumn{13}{|c|}{ Fórmula química calculada à base de 22 oxigênios } \\
\hline $\mathrm{Si}$ & 5,90 & 5,99 & 5,92 & 5,82 & 5,94 & 5,79 & 5,84 & 5,80 & 5,81 & 5,85 & 5,82 & 5,84 \\
\hline${ }^{\mathrm{IV}} \mathrm{Al}$ & 2,10 & 2,01 & 2,08 & 2,18 & 2,06 & 2,21 & 2,16 & 2,20 & 2,19 & 2,15 & 2,18 & 2,16 \\
\hline Sítio tet. & 8 & 8 & 8 & 8 & 8 & 8 & 8 & 8 & 8 & 8 & 8 & 8 \\
\hline${ }^{\mathrm{V}} \mathrm{Al}$ & 0,80 & 0,95 & 0,78 & 0,74 & 0,93 & 0,77 & 0,80 & 0,75 & 0,82 & 0,71 & 0,68 & 0,63 \\
\hline $\mathrm{Ti}$ & 0,28 & 0,29 & 0,33 & 0,19 & 0,21 & 0,27 & 0,28 & 0,31 & 0,29 & 0,28 & 0,26 & 0,30 \\
\hline $\mathrm{Fe}$ & 2,44 & 2,19 & 2,41 & 2,64 & 2,47 & 2,56 & 2,43 & 2,53 & 2,47 & 2,46 & 2,48 & 2,47 \\
\hline$M n$ & 0,07 & 0,06 & 0,05 & 0,06 & 0,09 & 0,07 & 0,06 & 0,03 & 0,05 & 0,07 & 0,04 & 0,07 \\
\hline $\mathrm{Mg}$ & 1,77 & 1,80 & 1,78 & 1,89 & 1,74 & 1,80 & 1,84 & 1,79 & 1,78 & 1,95 & 2,07 & 2,02 \\
\hline Sítio oct. & 5,36 & 5,29 & 5,35 & 5,53 & 5,43 & 5,47 & 5,42 & 5,41 & 5,42 & 5,47 & 5,53 & 5,50 \\
\hline $\mathrm{Ca}$ & 0,03 & 0,06 & 0,03 & 0,03 & 0,02 & 0,02 & 0,03 & 0,03 & 0,03 & 0,03 & 0,02 & 0,02 \\
\hline $\mathrm{K}$ & 1,94 & 1,77 & 1,87 & 1,94 & 1,81 & 1,93 & 1,90 & 1,94 & 1,87 & 1,88 & 1,88 & 1,89 \\
\hline Sítio A & 1,97 & 1,83 & 1,90 & 1,97 & 1,83 & 1,95 & 1,93 & 1,97 & 1,90 & 1,91 & 1,90 & 1,91 \\
\hline
\end{tabular}


o das reequilibradas (Figura 5B). Apresentam afinidades com biotitas de rochas cálcio-alcalinas (Nachit et al., 1985; Figura 5C) e suas razões $\mathrm{Fe} /(\mathrm{Fe}+\mathrm{Mg})$ sugerem condições de fugacidade de oxigênio moderadas a altas durante a cristalização dessas rochas (Anderson \& Smith, 1995; Figura 5D).

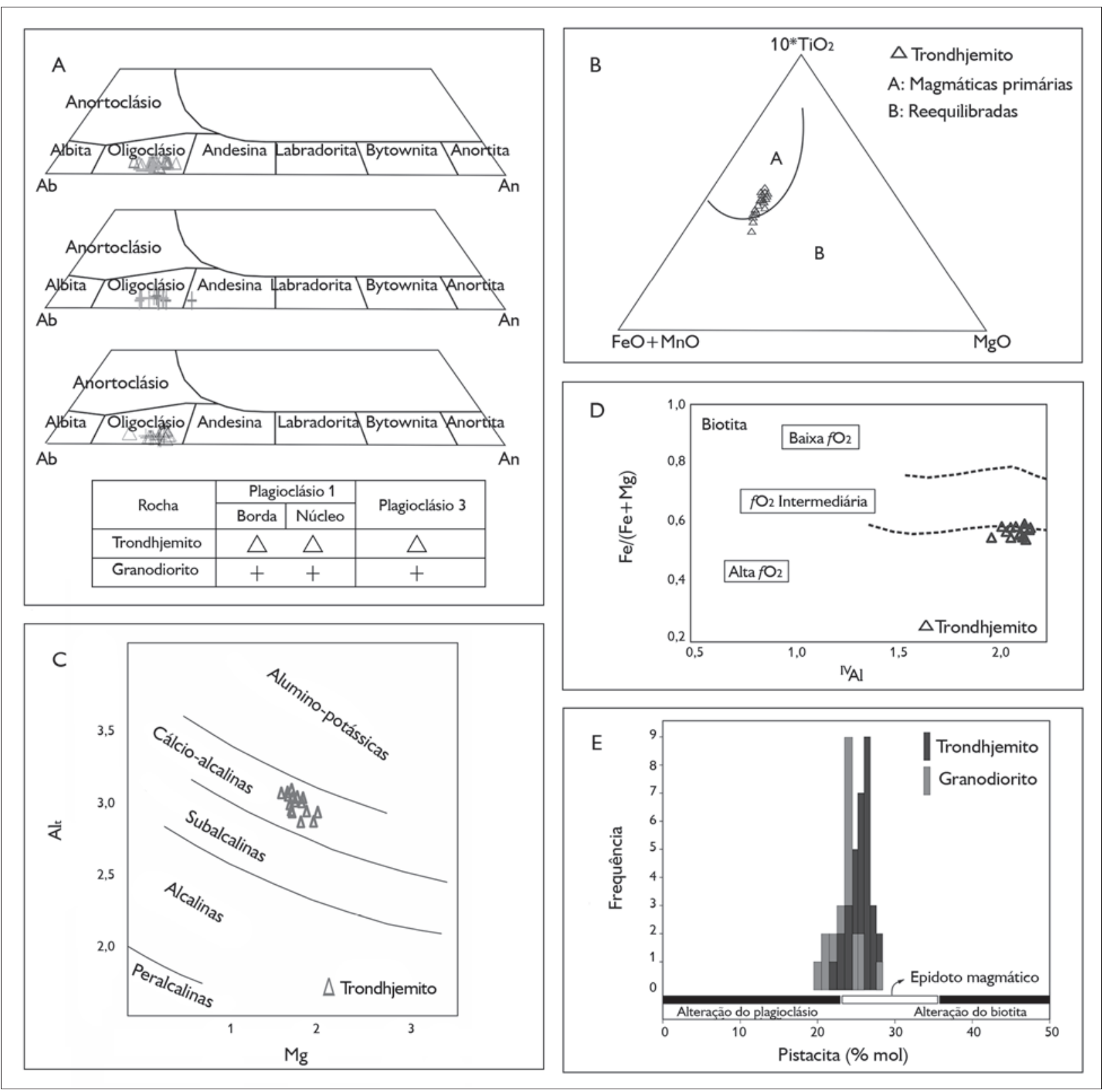

Figura 5. A) Diagrama Ab-Or-An com destaque para a aresta Ab-An para a classificação dos plagioclásios estudados a partir de análises químicas semiquantitativas; B) diagrama (FeO+MnO)-(10* $\left.\mathrm{TiO}_{2}\right)-\mathrm{MgO}$ de Nachit et al. (2005) para classificação de biotitas; $\mathrm{C}$ ) diagrama $\mathrm{Al}$ versus $\mathrm{Mg}$ (Nachit et al., 1985) para discriminar diferentes famílias magmáticas; D) diagrama de classificação de biotitas baseado na razão Fe/(Fe+Mg) versus Alv (Anderson \& Smith, 1995), mostrando as possíveis condições de fugacidade de oxigênio durante a cristalização das rochas estudadas; E) histograma do conteúdo de pistacita (\% mol) em Epidoto 1 das rochas estudadas. A relação entre variação composicional e origem dos epidotos expressa no diagrama se baseia em Tulloch (1979).




A muscovita exibe lamelas subédricas de granulação média a fina, dispostas paralelamente à orientação da biotita. Seus contatos são retos com este mineral, sugerindo equilíbrio entre essas fases.

O epidoto apresenta dois aspectos texturais distintos:

- Epidoto 1: forma cristais euédricos a subédricos com faces bem definidas (Figura 4G), por vezes envolvendo núcleos de allanita. Está comumente associado à biotita e mostra contatos perfeitamente automorfos com as lamelas da mesma, ao passo que costuma exibir contornos irregulares quando em contato com quartzo e feldspatos. Os cristais de Epidoto 1 analisados por EDS no MEV (Figura 4H) são todos representativos dessa variedade de epidoto (Tabela 4) e apresentam teores de pistacita que variam de $23,8 \%$ a $27,6 \%$, situados, em sua maioria, no intervalo registrado em epidotos de origem magmática (Tulloch, 1979; Figura 5E). Entretanto, como o fechamento das análises de Epidoto 1 por EDS não foi o ideal (Tabela 4; valores bem acima de 100\%, atingindo $>110 \%$ no caso da amostra PFR-33A), os conteúdos de pistacita no Epidoto 1 aqui obtidos devem ser vistos com reservas, devendo ser verificados no futuro por meio de análises mais precisas com microssonda eletrônica. Outro aspecto a ser considerado é que foram analisados cristais de Epidoto 1 de apenas uma amostra de trondhjemito e duas de granodiorito. Seria indispensável, portanto, um número mais elevado de análises desse mineral em amostras de tonalitos e trondhjemitos para permitir conclusões mais seguras a respeito da origem do Epidoto 1 nessas variedades.

Tabela 4. Análises semiquantitativas por EDS de epidoto da associação tonalito-trondhjemito-granodiorito do leste do Subdomínio de Transição. Legendas: Ep1 $=$ Epidoto 1; PS $=\left(\mathrm{Fe}^{+3} / \mathrm{Fe}^{+3}+\mathrm{Al}\right) \times 100$.

\begin{tabular}{|c|c|c|c|c|c|c|c|c|c|c|c|c|c|c|c|}
\hline \multirow{3}{*}{$\begin{array}{c}\text { Litologia } \\
\text { Amostra } \\
\text { Mineral }\end{array}$} & \multirow{2}{*}{\multicolumn{5}{|c|}{ Bt-trondhjemito }} & \multicolumn{10}{|c|}{ Bt-granodiorito } \\
\hline & & & & & PFA-14 & \multicolumn{3}{|c|}{ MYF-67 } & \multicolumn{7}{|c|}{ PFR-33A } \\
\hline & Ep1 & Ep1 & Ep1 & Ep1 & Ep1 & Ep1 & Ep1 & Ep1 & Ep1 & Ep1 & Ep1 & Ep1 & Ep1 & Ep1 & Ep1 \\
\hline Análise & C2-1 & C2-3 & C2-4 & C2-5 & $C 2-6$ & C1-2 & C1-3 & C1-5 & $C 2-1$ & C2-2 & C2-3 & C2-4 & $C 2-5$ & $C 2-6$ & C2-7 \\
\hline $\mathrm{SiO}_{2}$ & 41,96 & 42,02 & 41,70 & 41,39 & 41,59 & 42,49 & 42,38 & 42,41 & 44,51 & 44,00 & 44,48 & 44,53 & 44,88 & 44,77 & 44,40 \\
\hline $\mathrm{TiO}_{2}$ & 0,22 & 0,09 & 0,08 & 0,21 & 0,22 & 0,13 & 0,18 & 0,23 & 0,24 & 0,25 & 0,10 & 0,15 & 0,19 & 0,21 & 0,23 \\
\hline $\mathrm{Al}_{2} \mathrm{O}_{3}$ & 24,29 & 24,58 & 24,88 & 24,98 & 24,19 & 24,83 & 24,47 & 24,97 & 25,04 & 26,00 & 26,09 & 25,74 & 25,61 & 25,71 & 25,70 \\
\hline $\mathrm{Fe}_{2} \mathrm{O}_{3}$ & 13,41 & 13,73 & 12,26 & 12,47 & 13,56 & 12,59 & 13,38 & 12,30 & 14,95 & 14,81 & 15,13 & 14,67 & 15,29 & 14,69 & 14,60 \\
\hline $\mathrm{MgO}$ & 0,05 & 0,12 & 0,02 & 0,03 & 0,05 & 0,04 & 0,05 & 0,01 & 0,06 & 0,07 & 0,16 & 0,16 & 0,11 & 0,13 & 0,04 \\
\hline $\mathrm{MnO}$ & 0,37 & 0,23 & 0,37 & 0,35 & 0,29 & 0,67 & 0,27 & 0,73 & 0,38 & 0,46 & 0,44 & 50 & 0,28 & 0,40 & 0,48 \\
\hline $\mathrm{CaO}$ & 22,63 & 23,19 & 23,59 & 23,52 & 23,36 & 22,97 & 23,05 & 22,86 & 26,08 & 25,97 & 26,03 & 26,16 & 25,86 & 26,48 & 25,95 \\
\hline Total & 102,9 & 104,0 & 102,9 & 102,9 & 103,3 & 103,7 & 103,8 & 103,5 & 111,3 & 111,6 & 112,4 & 111,9 & 112,2 & 112,4 & 111,4 \\
\hline \multicolumn{16}{|c|}{ Fórmula química calculada à base de 13 oxigênios } \\
\hline $\mathrm{Si}$ & 3,27 & 3,25 & 3,25 & 3,23 & 3,24 & 3,28 & 3,28 & 3,28 & 3,24 & 3,19 & 3,20 & 3,22 & 3,23 & 3,22 & 3,22 \\
\hline $\mathrm{Ti}$ & 0,01 & 0,01 & 0,00 & 0,01 & 0,01 & 0,01 & 0,01 & 0,01 & 0,01 & 0,01 & 0,01 & 0,01 & 0,01 & 0,01 & 0,01 \\
\hline $\mathrm{Al}$ & 2,23 & 2,24 & 2,29 & 2,30 & 2,22 & 2,26 & 2,23 & 2,28 & 2,15 & 2,23 & 2,21 & 2,19 & 2,18 & 2,18 & 2,20 \\
\hline $\mathrm{Fe}^{+3}$ & 0,79 & 0,80 & 0,72 & 0,73 & 0,80 & 0,73 & 0,78 & 0,72 & 0,82 & 0,81 & 0,82 & 0,80 & 0,83 & 0,80 & 0,80 \\
\hline $\mathrm{Mg}$ & 0,01 & 0,01 & 0,00 & 0,00 & 0,01 & 0,00 & 0,01 & 0,00 & 0,01 & 0,01 & 0,02 & 0,02 & 0,01 & 0,01 & 0,00 \\
\hline $\mathrm{Mn}$ & 0,02 & 0,01 & 0,02 & 0,02 & 0,02 & 0,04 & 0,02 & 0,05 & 0,02 & 0,03 & 0,03 & 0,03 & 0,02 & 0,02 & 0,03 \\
\hline $\mathrm{Ca}$ & 1,87 & 1,90 & 1,95 & 1,94 & 1,93 & 1,88 & 1,89 & 1,87 & 2,01 & 1,99 & 1,98 & 2,00 & 1,97 & 2,02 & 1,99 \\
\hline PS & 26,08 & 26,29 & 23,93 & 24,18 & 26,37 & 24,47 & 25,89 & 23,94 & 27,61 & 26,69 & 27,03 & 26,69 & 27,61 & 26,74 & 26,62 \\
\hline
\end{tabular}


- Epidoto 2: apresenta-se como cristais anédricos muito finos, produto de alteração de plagioclásio.

Os minerais acessórios são: allanita em cristais subédricos, finos, por vezes zonada; opacos em cristais finos subédricos a anédricos, os quais podem apresentar coroas de titanita e epidoto; titanita em agregados máficos; apatita e zircão, em diminutos cristais subédricos, inclusos em plagioclásio, biotita e quartzo.

\section{GEOQUÍMICA}

As análises químicas dos elementos maiores, menores e traço de amostras representativas das diferentes variedades petrográficas da associação TTG estudada foram realizadas na ACME Analytical Laboratories e são apresentadas na Tabela 5. Os elementos maiores e menores foram analisados por ICP-ES, enquanto que os elementos-traço, inclusive os elementos terras raras, foram dosados por ICP-MS. Os métodos empregados e os limites de detecção são informados em AcmeLabs (s.d.).

As rochas estudadas possuem conteúdos de sílica variando de $59,3 \%$ a $74,35 \%$, com os enclaves mostrando os menores valores. Com exceção dos enclaves, todas as amostras analisadas apresentaram conteúdo de elementos ferromagnesianos relativamente baixos $\left(\mathrm{Fe}_{2} \mathrm{O}_{3}+\mathrm{MgO}+\mathrm{MnO}+\mathrm{TiO}_{2}<5 \%\right)$ e valores de $\# \mathrm{Mg}$ moderados $(0,27-0,47)$. A alumina é alta na maioria das amostras $\left(\mathrm{Al}_{2} \mathrm{O}_{3}>15 \%\right)$ e tende a decrescer nas variedades mais ricas em sílica. Tais valores permitem classificar as rochas estudadas como trondhjemitos portadores de alto $\mathrm{Al}_{2} \mathrm{O}_{3}$ (Barker, 1979). O conteúdo de álcalis mostra variações significativas nas variedades petrográficas analisadas. Tomando por base os critérios de Moyen \& Martin (2012) para classificação de TTG arqueanos e, entre outros fatores, as variações dos conteúdos de $\mathrm{K}_{2} \mathrm{O}$ e das razões $\mathrm{Na}_{2} \mathrm{O}$ / $\mathrm{K}_{2} \mathrm{O}$, foi possível discriminar duas composições distintas entre as rochas analisadas. Aquelas com 0,5 $<\mathrm{K}_{2} \mathrm{O}<$ $2 \%$ são classificadas como tonalitos e trondhjemitos, enquanto as rochas com $\mathrm{K}_{2} \mathrm{O}>2 \%$ são consideradas granodioritos. Essa discriminação geoquímica é, de modo geral, coincidente com a classificação petrográfica feita com base em composições modais, segundo as regras da Subcomissão de Nomenclatura de Rochas Ígneas do IUGS (Le Maitre, 2002) para a maioria das amostras estudadas. No entanto, os resultados geoquímicos apontaram afinidades granodioríticas para algumas amostras (PFR-1, PFR-10A, MYF-48B, PFR-24, MYF-1), para as quais os dados modais indicavam composições trondhjemíticas. Cabe, no entanto, ressaltar que no diagrama Q-A-P (Figura 3) tais amostras se situam, em geral, muito próximas do limite entre os campos dos granodioritos e trondhjemitos, sendo admissível que, nas análises modais realizadas nessas amostras, o conteúdo modal de microclina tenha sido ligeiramente subestimado. A classificação petrográfica pôde ser testada ainda com a aplicação do diagrama P-Q (Figura 9E), discutido adiante.

Nos tonalitos e trondhjemitos, $\mathrm{K}_{2} \mathrm{O}$ varia de $0,7 \%$ a $2,0 \%$ e $\mathrm{Na}_{2} \mathrm{O}$ é superior a $5 \%$ na maioria das amostras, enquanto que, nos granodioritos, $\mathrm{K}_{2} \mathrm{O}$ varia de $2,2 \%$ a $3,64 \%$ e $\mathrm{Na}_{2} \mathrm{O}$ se situa geralmente entre $4 \%$ e $5 \%$. Os trondhjemitos têm baixas razões $\mathrm{K}_{2} \mathrm{O} / \mathrm{Na}_{2} \mathrm{O}$ (média de 0,26 ), as quais são acompanhadas por teores relativamente elevados de $\mathrm{CaO}$ (média de 2,81\%), quando comparados com os granodioritos, que apresentam como razão $\mathrm{K}_{2} \mathrm{O} /$ $\mathrm{Na}_{2} \mathrm{O}$ a média de 0,63 e conteúdo médio de $\mathrm{CaO}$ de 2,16\% (Tabela 5). As características geoquímicas mencionadas são inteiramente compatíveis com aquelas propostas em recente definição de TTG (Moyen \& Martin, 2012).

As amostras da associação TTG exibem, em diagramas de Harker para $\mathrm{Al}_{2} \mathrm{O}_{3}, \mathrm{TiO}_{2}, \mathrm{Fe}_{2} \mathrm{O}_{3}, \mathrm{MgO}$, $\mathrm{CaO}$ e $\mathrm{P}_{2} \mathrm{O}_{5}$, correlação negativa com a sílica (Figuras 6A-6F). Por outro lado, $\mathrm{Na}_{2} \mathrm{O}$ e $\mathrm{K}_{2} \mathrm{O}$ exibem variações acentuadas em amostras com teores de sílica similares, embora, para $\circ \mathrm{Na}_{2} \mathrm{O}$ e para as amostras de tonalitos e trondhjemitos, também haja evidência de correlação negativa com a sílica (Figuras 6G-6H). No entanto, em termos de $\mathrm{K}_{2} \mathrm{O}$, os granodioritos fogem inteiramente a essa tendência, pois possuem valores muito elevados de $\mathrm{K}_{2} \mathrm{O}$ para teores de sílica similares, quando comparados com os tonalitos e trondhjemitos. 


\begin{tabular}{|c|c|c|c|c|c|c|c|c|c|c|c|c|c|c|c|c|c|c|c|c|c|c|c|c|c|c|c|}
\hline \multirow{11}{*}{ 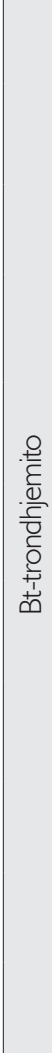 } & $\stackrel{\Perp}{\Sigma}$ &  & $\stackrel{+}{n}$ & $\frac{6}{0}$ & $\stackrel{\text { ̂}}{\leftarrow}$ & $\stackrel{\infty}{\stackrel{\infty}{=}}$ & 吕 & $\bar{\delta}$ &  & $\begin{array}{l}\text { 今ે } \\
\text { ஸू }\end{array}$ & $\stackrel{0}{\stackrel{0}{0}}$ & $\begin{array}{l}2 \\
0 \\
O\end{array}$ & $\widetilde{\sigma}$ & $\begin{array}{l}\infty \\
\alpha\end{array}$ & $\frac{n}{6}$ & $\frac{\dot{\sigma}}{\AA}$ & $\stackrel{\infty}{\Gamma}$ & 으 & 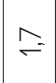 & $\stackrel{\sigma}{\mathrm{v}}$ & $m$ & $\hat{o}^{-}$ & $\stackrel{\stackrel{\sim}{n}}{\stackrel{\nu}{\sim}}$ & m & $\stackrel{\stackrel{n}{*}}{\sim}$ & $\tilde{\sigma}$ & $\neq$ \\
\hline & 夰 & $\stackrel{\sim}{\sim}$ & $\stackrel{m}{n}$ & $\frac{0}{0}$ & $\begin{array}{l}\sigma \\
\ddot{\forall}\end{array}$ & $\cong$ & $\stackrel{\stackrel{n}{m}}{\sigma}$ & $\tilde{\sigma}$ & $\stackrel{\bar{m}}{\sim}$ & $\begin{array}{l}\infty \\
\nabla^{-}\end{array}$ & $\stackrel{\infty}{\stackrel{\circ}{=}}$ & Ö. & on & $\alpha^{2}$ &  &  & \& & $\tilde{\sigma}$ & $\bar{F}$ & $\hat{\mathrm{i}}$ & $\stackrel{\stackrel{\sim}{\leftarrow}}{\forall}$ & $\begin{array}{l}0 \\
0 \\
0\end{array}$ & $\underline{m}$ & $\stackrel{\infty}{0}^{-}$ & $a$ & $\stackrel{\stackrel{n}{O}}{\circ}$ & 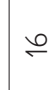 \\
\hline & $\sum_{\Sigma}^{\perp}$ & in & $\bar{n}$ & $\underset{\widetilde{\sigma}}{\bar{\sigma}}$ & $\stackrel{\stackrel{\sim}{*}}{\stackrel{F}{-}}$ & $\stackrel{\Re}{\stackrel{n}{\sim}}$ & $\underset{f}{\tilde{f}}$ & 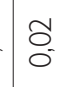 & 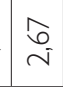 & $\begin{array}{l}\alpha \\
\underset{\sigma}{*}\end{array}$ & పू & O̊. & ẗ & $\begin{array}{l}\infty \\
\alpha \\
\alpha\end{array}$ & 昰 & $\stackrel{m}{\eta}$ & $\bar{\Phi}$ & 옴 & $\stackrel{\sim}{m}$ & $\stackrel{0}{m}$ & $\bar{m}$ & $\hat{0}$ &  & $\hat{0}$ & $\wedge$ & 0 & $\stackrel{\infty}{ }$ \\
\hline & $\sum_{\Sigma}^{\Perp}$ & $a$ & $\stackrel{\stackrel{n}{N}}{\mathbb{N}}$ & $\bar{\nwarrow}$ & $\stackrel{\Perp}{ }$ & $\stackrel{a}{i}$ & $\stackrel{\Perp}{\circ}$ & O̊ & $\stackrel{\sqrt[m]{v}}{\sim}$ & 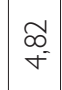 & $\stackrel{\stackrel{\leftrightarrow}{\infty}}{=}$ & $\bar{\delta}$ & $\tilde{\sigma}$ & $\vec{\sigma}$ & $\begin{array}{l}\mathscr{m} \\
\infty \\
\infty\end{array}$ & $\bar{m}$ & $\underset{f}{\stackrel{+}{f}}$ & $\stackrel{m}{m}$ & $\stackrel{\stackrel{n}{\prime}}{=}$ & $\stackrel{m}{\nabla}$ & $\stackrel{\mathcal{F}}{\leftarrow}$ & $\begin{array}{l}\Delta \\
0\end{array}$ & $\underline{\sigma}$ & $0^{\circ}$ & $\begin{array}{l}\sigma^{-} \\
m^{2}\end{array}$ & $\tilde{O}$ & 으 \\
\hline & 迠 & in & $\bar{N}$ & $\stackrel{d}{\stackrel{\Delta}{0}}$ & $\stackrel{m}{\stackrel{n}{L}}$ & $\stackrel{2}{i}$ & $\stackrel{\circ}{\circ}$ & $\tilde{\sigma}_{0}$ & $\stackrel{\substack{\infty \\
\sim}}{\sim}$ & 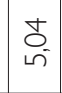 & $\stackrel{0}{=}$ & 8 & $\tilde{o}$ & $\sigma^{\circ}$ & $\widetilde{N}$ & $\begin{array}{l}\sigma \\
\stackrel{5}{m} \\
\end{array}$ & $\stackrel{\stackrel{\vartheta}{q}}{ }$ & ᄋे & $m_{m}^{m}$ & $m$ & $m$ & $\stackrel{t}{\sigma}$ & ڤ̂- & $\stackrel{\infty}{\infty}$ & $\begin{array}{l}\sigma^{2} \\
\sigma^{2}\end{array}$ & $\stackrel{m}{o}$ & $\neq$ \\
\hline & 畄 & $\stackrel{\wp}{+}$ & $\stackrel{F}{=}$ & $\overline{\widetilde{\sigma}}$ & 占 & 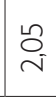 & 苋 & 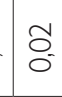 & $\stackrel{m}{\sim}$ & ָ̃ & $\stackrel{\vartheta}{\sigma}$ & Oे & $\tilde{o}$ & $\begin{array}{l}6 \\
\sigma\end{array}$ & $\stackrel{\beth}{\beth}$ & $\overline{\bar{m}}$ & F & $\stackrel{\Xi}{\varrho}$ & $\hat{\sigma}^{-}$ & $\tilde{\tau}$ & $\bar{i}$ & $\stackrel{0}{\circ}$ & $\stackrel{\stackrel{\Omega}{-}}{\stackrel{2}{2}}$ & $\hat{\sigma}^{\prime}$ & $\stackrel{\stackrel{\llcorner}{m}}{\dot{m}^{\prime}}$ & $\begin{array}{l}\infty \\
0 \\
0\end{array}$ & ণ \\
\hline & $\sum_{\Sigma}^{\Perp}$ & เి & $\stackrel{b}{i}$ & $\stackrel{\stackrel{\sim}{\sigma}}{\tilde{\sigma}}$ & $\stackrel{t}{\underline{\sigma}}$ & $\stackrel{t}{\sim}$ & $\stackrel{0}{\circ}$ & $\tilde{\sigma}_{0}$ & $\underset{\sim}{\mathcal{J}}$ & $\begin{array}{l}\infty \\
0 \\
\text { in }\end{array}$ & $\sim$ & $\begin{array}{l}\infty \\
0 \\
0\end{array}$ & m & $\frac{1}{2}$ & 売 & 8 & $\hat{\vartheta}$ & $\Xi$ & $\widetilde{N}$ & $\stackrel{\sim}{m}$ & $\stackrel{\sigma}{=}$ & Oֵ & $\begin{array}{c}m \\
\stackrel{0}{\rightleftharpoons}\end{array}$ & $\stackrel{m}{\sim}$ & $\begin{array}{l}\infty \\
\nabla^{-}\end{array}$ & $\ddot{\sigma}$ & $\stackrel{\infty}{\sim}$ \\
\hline & 똠 & in & $\stackrel{\stackrel{n}{\Sigma}}{\Sigma}$ & $\bar{\sigma}$ & $\begin{array}{l}\sigma \\
\stackrel{\sigma}{\leftarrow}\end{array}$ & $\stackrel{\underset{\infty}{\infty}}{\leftarrow}$ & กิ & $\tilde{\sigma}$ & $\stackrel{\text { 岕 }}{m}$ & $\begin{array}{l}\alpha \\
\sigma \\
\sigma\end{array}$ & $\hat{0}$ & mo & ○. & $\sigma^{\alpha}$ & $\stackrel{ }{\mathrm{m}}$ & $\stackrel{\sim}{\sim}$ & $\bar{m}$ & 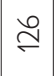 & $\stackrel{m}{\sim}$ & $\stackrel{m}{m}^{2}$ & $\stackrel{\curvearrowright}{i}$ & $\begin{array}{l}\dot{\sigma} \\
0\end{array}$ & $\begin{array}{l}m \\
\underline{0}\end{array}$ & $\stackrel{2}{0}$ & $\begin{array}{l}0 \\
0 \\
0\end{array}$ & $\stackrel{N}{\sim}$ & 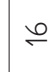 \\
\hline & 畄 & 冬 & 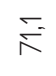 & $\frac{\infty}{0}$ & $\underset{v}{\sigma}$ & 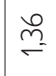 & f̊ & $\delta_{0}$ & 嵒 & $\begin{array}{l}\infty \\
\stackrel{\infty}{-1} \\
\text { ம் }\end{array}$ & $\stackrel{\Omega ِ}{=}$ & 8 & $\stackrel{m}{o}$ & 兄 & $\hat{\alpha}$ & $\stackrel{\stackrel{n}{2}}{\stackrel{m}{m}}$ & $\stackrel{\llcorner}{\infty}$ & $\risingdotseq$ & $\approx$ & $\bar{m}$ & 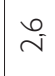 & $\stackrel{\sim}{\sigma}$ & $\stackrel{m}{\stackrel{2}{\sigma}}$ & to & $\stackrel{\infty}{m}^{-}$ & $\stackrel{n}{0}$ & ঃ \\
\hline & 땡 & $\stackrel{\nwarrow}{\leftrightarrows}$ & $\bar{R}$ & m & L̊ & $\underset{\mathrm{N}}{\mathrm{r}}$ & $\underset{\sigma}{\sigma}$ & $\tilde{O}$ & $\delta_{m}$ & \begin{tabular}{|l|} 
\\
$\stackrel{\infty}{0}$ \\
ம்
\end{tabular} & $\underset{F}{E}$ & 8 & $\sigma_{0}$ & a & $\bar{\delta}$ & $\stackrel{a}{m}$ & 字 & $\beth$ & $\approx$ & $\stackrel{0}{i}$ & $\stackrel{\sigma}{m}$ & $\stackrel{2}{0}$ & $\stackrel{o}{\stackrel{0}{-}}$ & $\stackrel{\sim}{0}$ & $\hat{m}$ & $\tilde{\sigma}$ & ஓ \\
\hline & $\sum_{\Sigma}^{\Perp}$ & $\underset{\sigma}{\sigma}$ & $a_{\sigma}^{m}$ & m & ֶ. & $\bar{m}$ & $\begin{array}{l}E \\
0 \\
0\end{array}$ & ठ & $\stackrel{\substack{\infty \\
\sim}}{\sim}$ & กี & $\stackrel{\Perp}{=}$ & o & ẗ & $\begin{array}{l}\infty \\
\alpha\end{array}$ & $\stackrel{m}{m}$ & 字 & $\stackrel{\stackrel{\leftrightarrow}{q}}{\sim}$ &  & ஸึ & $\stackrel{\mathcal{F}}{-}^{-}$ & กู & 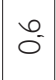 & $\begin{array}{l}\sigma \\
\stackrel{2}{\sigma}\end{array}$ & $\sigma_{0}$ & $\hat{\sigma}^{-}$ & $\stackrel{m}{0}$ & $\stackrel{\Perp}{\sim}$ \\
\hline \multirow{5}{*}{ 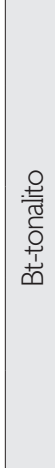 } & 똠 & 요 & $N$ & $\underset{0}{\dddot{O}}$ & if & $\underset{\tilde{\sigma}}{\tilde{i}}$ & $\frac{0}{0}$ & ஜ & $\vec{\sim}$ & \begin{tabular}{l}
$\infty$ \\
$\infty$ \\
\multirow{f}{*}{}
\end{tabular} & $\stackrel{t}{=}$ & $\underset{0}{\infty}$ & $\bar{\sigma}$ & $\stackrel{\infty}{\alpha}$ & 帛 & $\begin{array}{l}m \\
\stackrel{n}{m}\end{array}$ & $\stackrel{\mathscr{F}}{\mathscr{f}}$ & $\stackrel{\infty}{\rightleftharpoons}$ & $\bar{m}$ & $\stackrel{\alpha}{m}$ & $\stackrel{\stackrel{n}{m}}{m}$ & 0 & $\stackrel{\sigma}{\sigma}$ & - & \begin{tabular}{l}
$\infty$ \\
\hdashline \\
$\sim$
\end{tabular} & $\begin{array}{l}0 \\
0\end{array}$ & $\stackrel{m}{m}$ \\
\hline & 畄 & $\stackrel{\stackrel{\sim}{m}}{\mathrm{n}}$ & $E$ & $\overline{\widetilde{\sigma}}$ & ث̃ & $\stackrel{\infty}{\sim}$ & $\begin{array}{l}\bar{\sigma} \\
\overline{0}\end{array}$ & $\underset{\sigma}{\sigma}$ & $\stackrel{n}{\sim}$ & 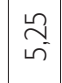 & 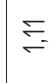 & Ö & $\hat{0}$ & $\alpha$ & $\stackrel{\stackrel{\sim}{~}}{\mathrm{~m}}$ & ন̀ & $\stackrel{\leftrightarrow}{\not{q}}$ & $\stackrel{\stackrel{ }{\rightleftharpoons}}{=}$ & $\stackrel{\stackrel{n}{\sim}}{\sim}$ & $\bar{m}$ & $\stackrel{2}{=}$ & $\hat{o}$ & $\stackrel{\curvearrowright}{\stackrel{-}{\sigma}}$ & $\stackrel{m}{=}$ & $\hat{i}$ & $\stackrel{\text { 응 }}{0}$ & ㅇ \\
\hline & $\stackrel{\Perp}{\sum}$ & $\stackrel{\varrho}{\infty}$ & $\stackrel{m}{\rho}$ & 夑 & Ë & $\stackrel{m}{m}$ & $\Xi$ & 8 & $m$ & $\underset{f}{\stackrel{f}{\leftarrow}}$ & $\stackrel{\stackrel{m}{m}}{=}$ & $\overline{0}$ & $0_{0}^{0}$ & $\begin{array}{l}\infty \\
\alpha \\
\alpha\end{array}$ & $\overline{\Phi_{0}}$ & $\begin{array}{l}0 \\
\dot{\infty}\end{array}$ & $\stackrel{\infty}{m}$ & 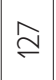 & $\stackrel{\Perp}{\beth}$ & $\stackrel{\dot{m}}{m}$ & Gु & $\begin{array}{l}\infty \\
0^{-}\end{array}$ & $\stackrel{\stackrel{\sim}{2}}{\rightleftharpoons}$ & $\stackrel{\Xi}{=}$ & $\begin{array}{l}\infty \\
0 \\
0\end{array}$ & $\bar{i}$ & $\mathscr{f}$ \\
\hline & 畄 & $\stackrel{\sim}{\sim}$ & $\bar{p}$ & $\underset{\tilde{\sigma}}{\tilde{\sigma}}$ & $\underset{\widetilde{C}}{\underline{\sigma}}$ & 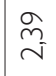 & : & 范 & $\begin{array}{l}\infty \\
\infty \\
\sim\end{array}$ & 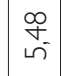 & $\stackrel{\text { go }}{=}$ & $\overline{0}$ & $\hat{0}$ & 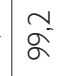 &  & $\stackrel{m}{r}$ & $\stackrel{\ddot{f}}{\forall}$ & $\bar{m}$ & $\stackrel{\sigma}{m}$ & $\stackrel{\sim}{m}$ & ติ & $\begin{array}{l}0 \\
0 \\
0\end{array}$ & $\stackrel{m}{\rightleftharpoons}$ & $0^{\circ}$ & $\begin{array}{l}\alpha \\
m^{2}\end{array}$ & $\stackrel{2}{0}$ & $\lesssim$ \\
\hline & $\sum_{\sum}^{\Perp}$ & $\stackrel{\sim}{\sim}$ & $\hat{\sigma}$ & $\stackrel{2}{o}$ & $\begin{array}{l}t \\
\sigma\end{array}$ & 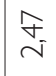 & $\begin{array}{l}0 \\
0 \\
0\end{array}$ & 范 & $\underset{m}{\Delta}$ & $\begin{array}{l}\underset{J}{J} \\
\text { ஸn }\end{array}$ & $\stackrel{\approx}{\approx}$ & E & t & $\begin{array}{l}\infty \\
\alpha \\
\sigma\end{array}$ & $\underset{\sim}{\stackrel{⿰}{\sim}}$ & 守 & 年 & กี & $\hat{m}$ & $\stackrel{m}{\forall}$ & $\stackrel{\infty}{m}$ & $\begin{array}{l}\dot{0} \\
\dot{0}\end{array}$ & $\stackrel{\stackrel{m}{\infty}}{\stackrel{\infty}{\rightleftharpoons}}$ & $=$ & $\sigma$ & $\ddot{\sigma}_{0}$ & ং \\
\hline \multirow{3}{*}{  } & 똠 & $\bar{m}$ & Нู & $\begin{array}{l}0 \\
0 \\
0\end{array}$ & $\stackrel{6}{\stackrel{6}{c}}$ & $\begin{array}{l}\hat{0} \\
\omega\end{array}$ & $\bar{i}$ & $0_{0}^{\circ}$ & $\underset{\tau}{\underset{\leftarrow}{Z}}$ & $\begin{array}{l}0 \\
\text { mi }\end{array}$ & $\stackrel{\Omega}{\sigma}$ & $\frac{\sigma}{\sigma}$ & - & $\hat{\alpha}^{-}$ & 苔 & $\begin{array}{c}m \\
\infty \\
\infty\end{array}$ & $\stackrel{2}{5}$ & $\stackrel{\text { m }}{\text { r }}$ & $\stackrel{\varrho}{\risingdotseq}$ & $\stackrel{\sim}{m}$ & $\underset{\sigma}{ }$ & $\hat{o}$ & 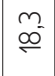 & ñ & $m^{2}$ & $\stackrel{m}{=}$ & ᄋे \\
\hline & 䋨 & $\stackrel{m}{\stackrel{m}{m}}$ & ํㅛ & ○. & 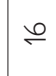 & $\stackrel{\forall}{\forall}$ & $\stackrel{\infty}{=}$ & $\bar{o}$ & F́ & $\stackrel{+}{*}$ & $\stackrel{m}{=}$ & 5 & ò & ๙ & $\underset{\nwarrow}{\mathbb{N}}$ & $\stackrel{\infty}{+}$ & $\begin{array}{l}\infty \\
\infty \\
m\end{array}$ & 프 & $\simeq$ & $\stackrel{+}{m}$ & ๓n & $\begin{array}{l}\infty \\
0 \\
0\end{array}$ & থ & $m$ & $m$ & $=$ & $\bar{\infty}$ \\
\hline & 別 & u & ๙ & $\stackrel{\dddot{Z}}{=}$ & 틈 & $\begin{array}{l}\stackrel{L}{0} \\
\infty\end{array}$ & ๙ू & Oे & 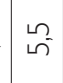 & $\stackrel{\stackrel{m}{m}}{m}$ & 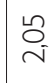 & 年 & $\hat{0}$ & $\begin{array}{l}\infty \\
\alpha\end{array}$ & $\begin{array}{l}\infty \\
\propto \\
\propto\end{array}$ & m & 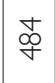 & $\underline{\tilde{b}}$ & $\begin{array}{l}\infty^{\circ} \\
\stackrel{\infty}{=}\end{array}$ & $\stackrel{\sim}{\sim}$ & $\sigma_{0}^{+}$ & $\hat{o}$ & $\begin{array}{l}\infty \\
0 \\
\underline{0}\end{array}$ & $\sim$ & $\stackrel{\stackrel{n}{n}}{m}$ & 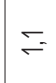 & $\underset{f}{ \pm}$ \\
\hline $\mid \begin{array}{l}\frac{\pi}{00} \\
0.0 \\
.0 \\
\end{array}$ & $\begin{array}{l}\frac{0}{6} \\
\text { ह }\end{array}$ & 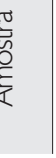 & $\begin{array}{l}\frac{\tilde{d}}{0} \\
\frac{0}{0} \\
\stackrel{0}{n}^{N}\end{array}$ & $\stackrel{\varrho}{\models}$ & $0^{m}$ & $O^{m}$ & $\sum_{\substack{\infty \\
\Sigma}}^{\infty}$ & $\sum_{\Sigma}^{\circ}$ &  & $\begin{array}{l}O \\
\stackrel{\pi^{0}}{Z}\end{array}$ & $\stackrel{\underset{\sim}{O}}{O}$ & $O_{\Omega^{n}}^{\infty}$ & u & 粂 & $\begin{array}{l}\widehat{\varepsilon} \\
\tilde{0} \\
\tilde{n} \\
\tilde{\infty}\end{array}$ & 요 & $\dot{s}$ & $\grave{N}$ & $\succ$ & 告 & z & 10 & $\mathbb{O}$ & $\mathcal{U}$ & $F$ & $\supset$ & $>$ \\
\hline
\end{tabular}






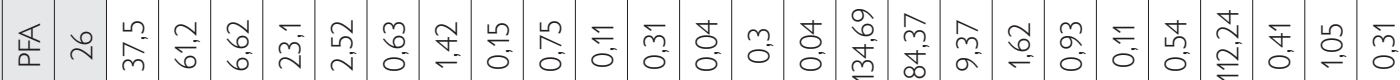

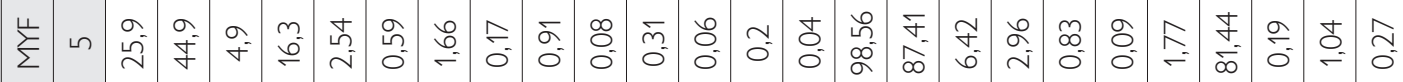



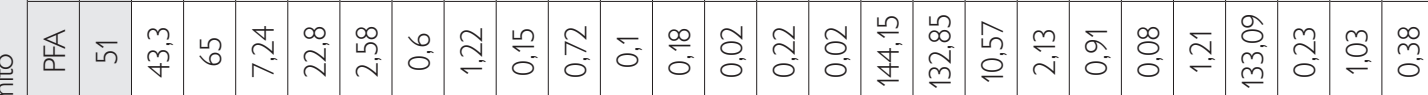


竞



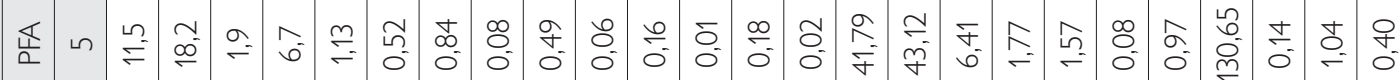
舀否

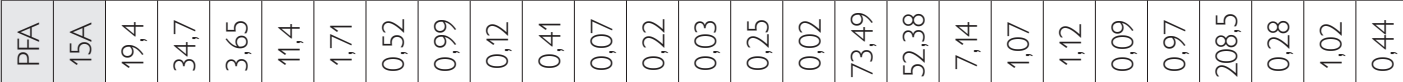

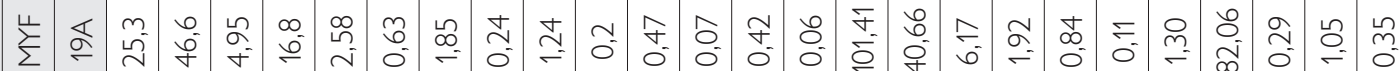

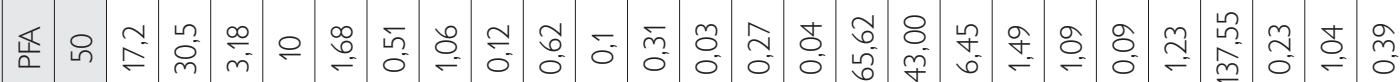

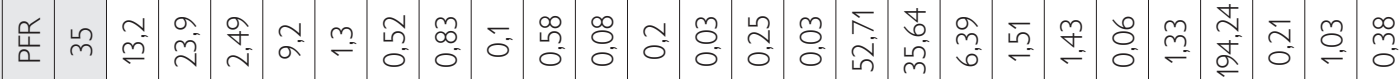

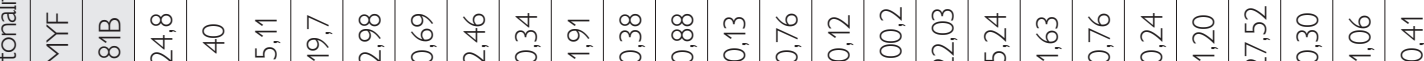
虫

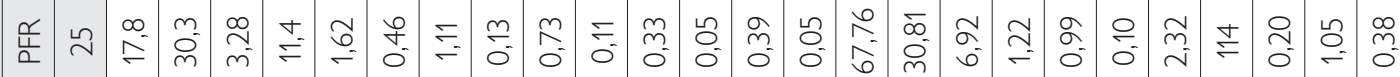

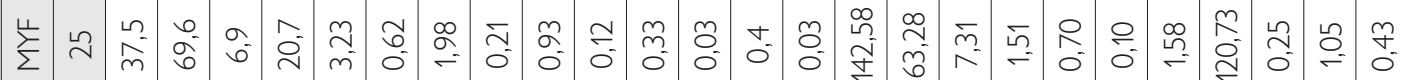

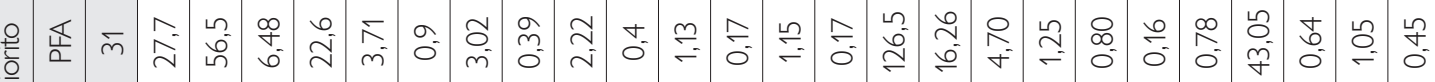

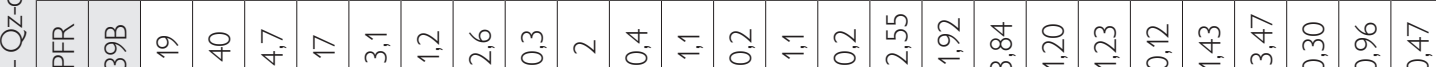



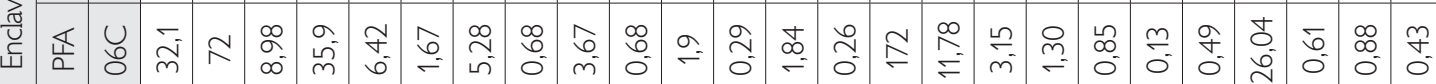

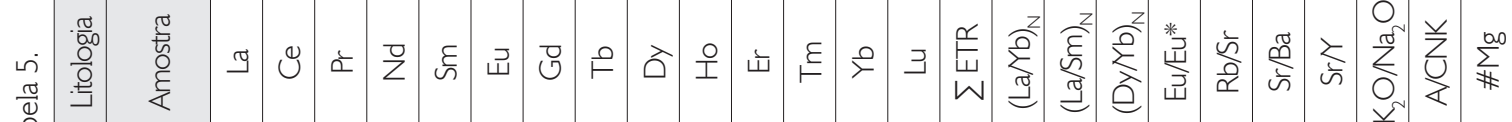








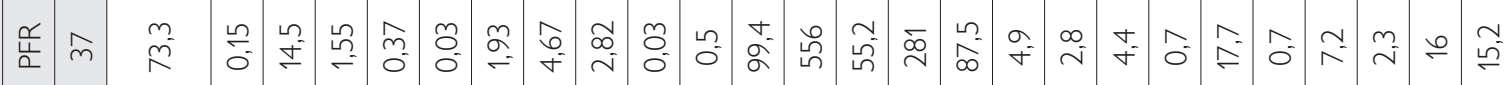

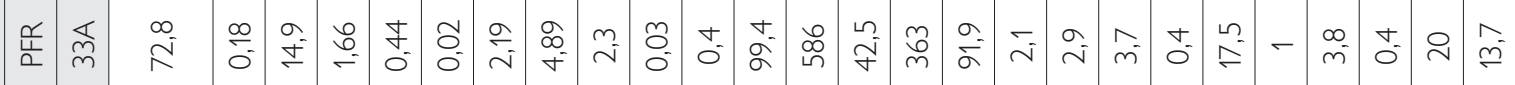

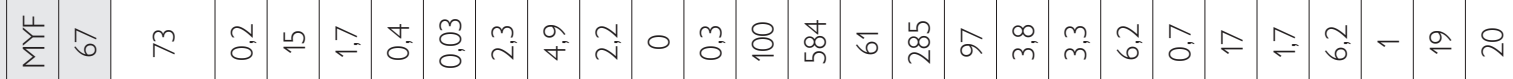


金

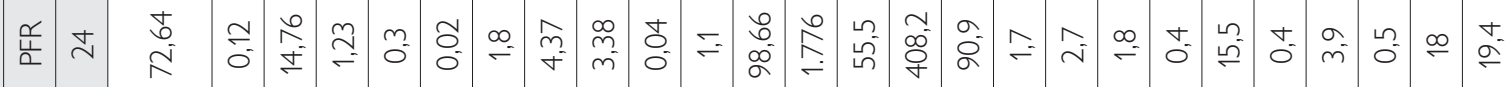

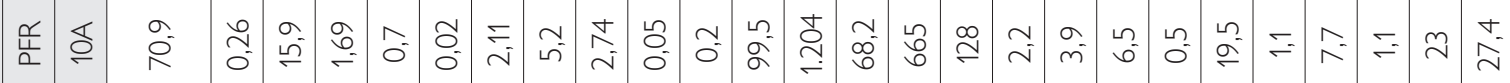

땃 ก

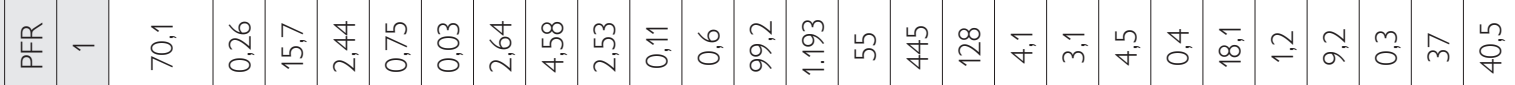








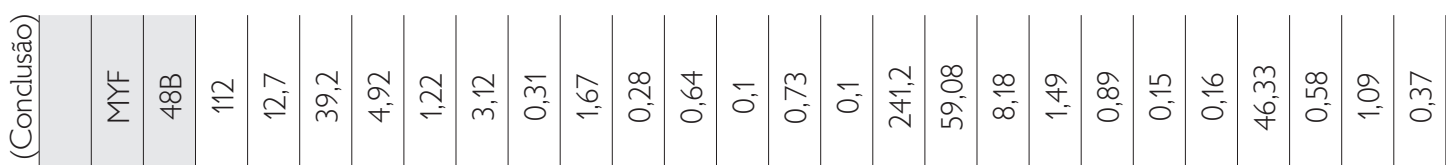



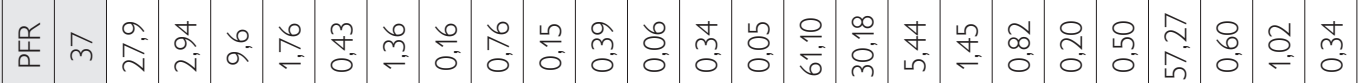

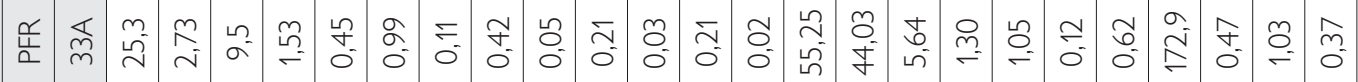

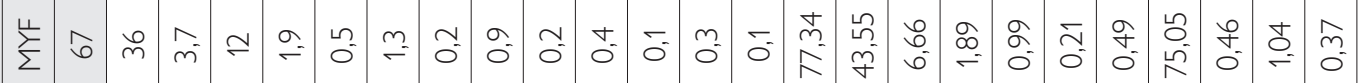

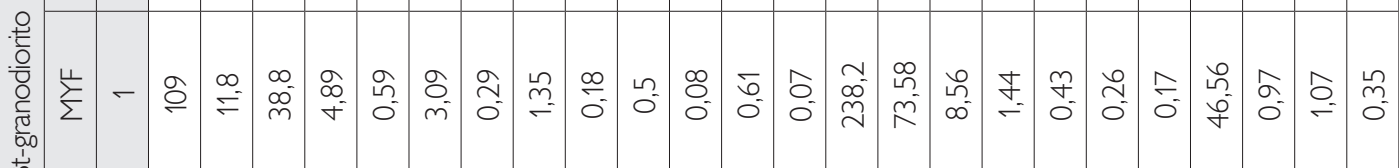
Фे

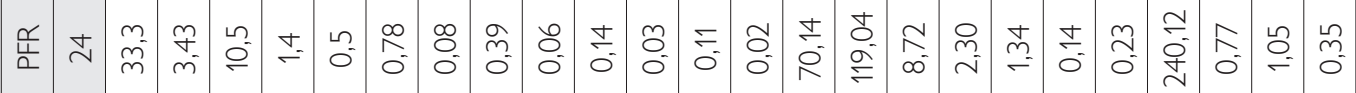



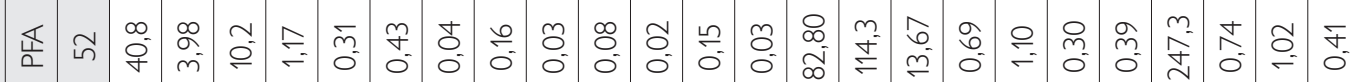

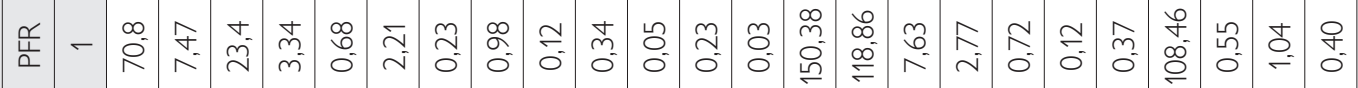

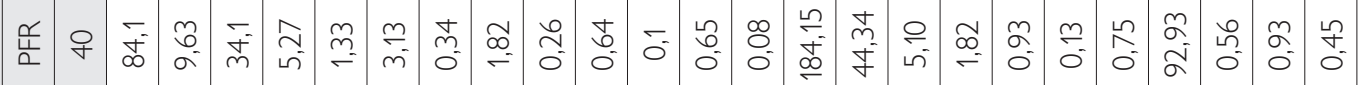

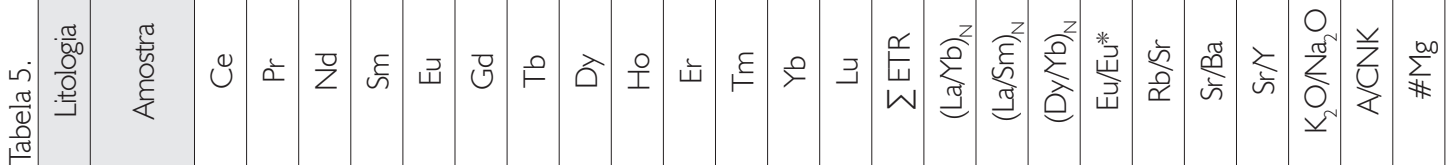



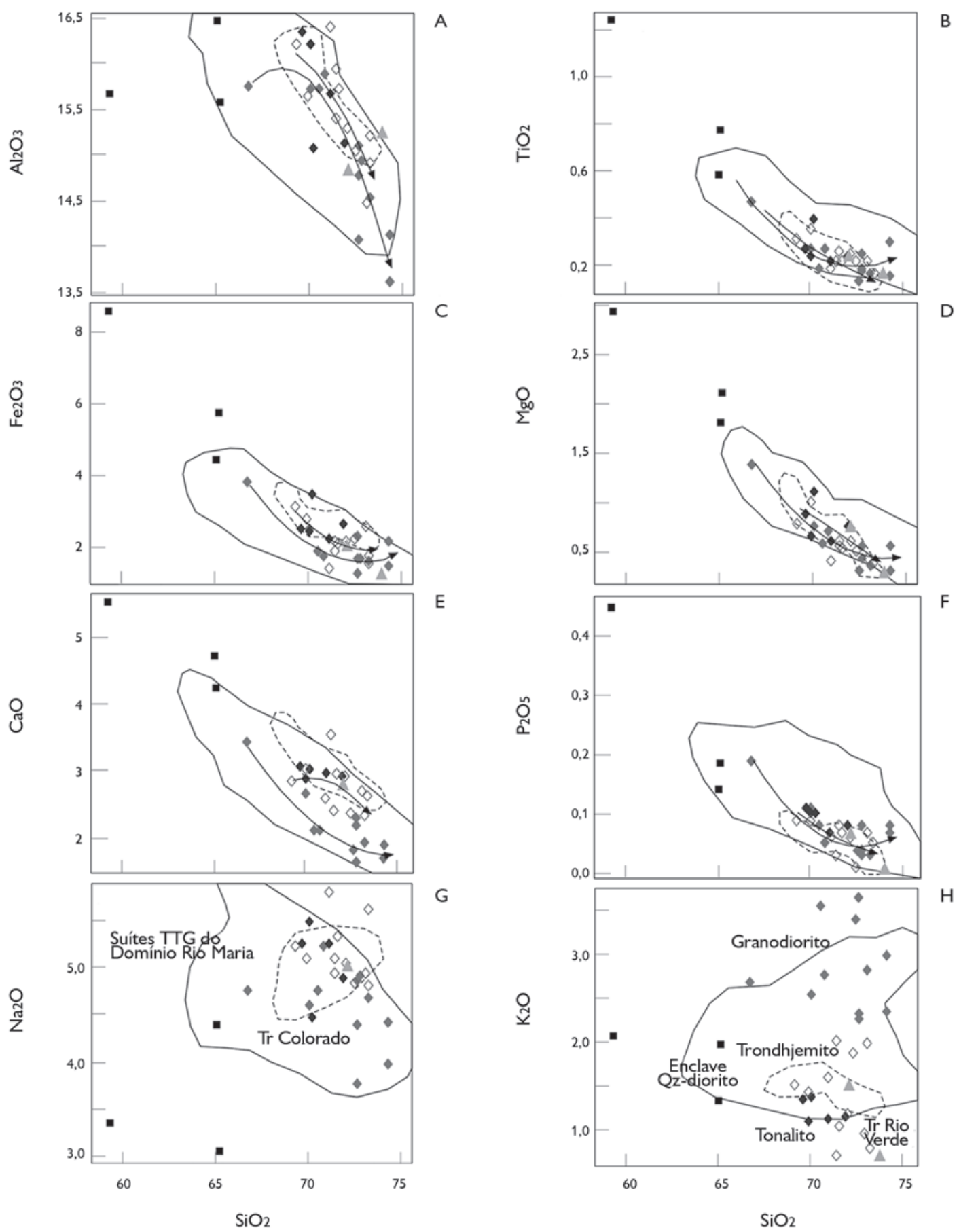

Figura 6. Diagramas de Harker para os óxidos de elementos maiores da associação TTG estudada, em comparação com as associações TTG da Província Carajás: A) Al $\mathrm{O}_{3}$; B) TiO ; C) $\mathrm{Fe}_{2} \mathrm{O}_{3}$; D) MgO; E) $\mathrm{CaO}$; F) $\mathrm{P}_{2} \mathrm{O}_{5}$; G) Na $\mathrm{O}$; H) $\mathrm{K}$ O. Fontes dos dados das suítes TTG: Domínio Rio Maria (Almeida et al., 2011); Trondhjemito Rio Verde (Feio et al., 2013); Trondhjemito Colorado (Silva et al., comunicação pessoal, 2013).




Na associação TTG estudada, o comportamento dos principais elementos-traço se mostra muito irregular (Figura 7), com variações acentuadas nos seus conteúdos em amostras com teores semelhantes de $\mathrm{SiO}_{2}$, O que impede a definição de tendências evolutivas. Em termos dos elementos litófilos, os trondhjemitos diferem dos granodioritos por serem empobrecidos em $\mathrm{Rb}$ e $\mathrm{Ba}$, bem como por apresentarem razões $\mathrm{Rb} / \mathrm{Sr}$ relativamente mais baixas. $\mathrm{O} \mathrm{Rb}$ mostra comportamento análogo ao do $\mathrm{K}_{2} \mathrm{O}$, com correlação negativa em relação à sílica para tonalitos e trondhjemitos e ampla dispersão de valores nos granodioritos (Figura 7A). O Ba também mostra distribuição contrastante para tonalitos/trondhjemitos e granodioritos, percebendo-se notável enriquecimento neste elemento em diversas amostras dos granodioritos (Figura 7C). No caso do Sr, os conteúdos nas duas variedades de rochas tendem a se superpor (Figura 7B). Em razão do exposto, as razões Sr/Ba (Figura 7D) são mais elevadas nos tonalitos e trondhjemitos (média de 1,24) em comparação com os granodioritos (média de 0,42), ao passo que ocorre o inverso com a razão Rb/Sr (Figura 7E), com valores médios de 0,09 e 0,18, respectivamente, nos tonalitos/trondhiemitos e granodioritos.

Em um tratamento estatístico, o método dos mínimos quadrados foi aplicado nos diagramas de Harker para identificar o grau de correlação (ou dispersão) e o tipo de curva (ou reta) envolvida na associação estudada. Dessa forma, os diagramas bivariantes para os diferentes elementos analisados evidenciaram, tanto para os tonalitos/trondhjemitos quanto para os granodioritos, coeficientes de correlação polinomial mais elevado do que os obtidos para as correlações lineares. Em geral, a grande maioria dos elementos maiores apresentou correlações moderadas a fortemente negativas para a associação estudada, exceto para o $\mathrm{K}_{2} \mathrm{O}$, que mostrou correlação nula. Para os elementos-traço, o Rb exibiu correlações moderadas negativas e o Ba mostrou correlações fracamente positivas. Os demais elementos apresentaram correlações pouco significativas ou dispersões. Esses dados indicam que os processos de evolução magmática envolveram, em algum momento, mudança nas assembleias mineralógicas relacionadas a esses elementos, durante processos de cristalização fracionada e/ou fusão parcial. As dispersões observadas parecem estar relacionadas com o fato de os elementos mais incompatíveis ( $\mathrm{Na}, \mathrm{K}, \mathrm{Ba}, \mathrm{Zr}$ ) serem extremamente móveis em processos metassomáticos e/ou intempéricos, o que mascara suas concentrações originais.

De modo geral, Y e Yb apresentam teores relativamente constantes para as diferentes amostras (Figuras 7G-7H). O Zr apresenta certa dispersão, mas tende a definir correlação negativa com a sílica (Figura 7F).

Os padrões de elementos terras raras (ETR; Figura 8) normalizados em relação ao condrito (Evensen et al., 1978) revelam que os trondhjemitos exibem um acentuado fracionamento de ETR pesados em relação aos leves $\left(22,03<\left[\mathrm{La} / \mathrm{Yb}_{\mathrm{N}}\right]<132,85\right.$; Tabela 5), com anomalias de Eu muito discretas ou ausentes (Eu/Eu* variando geralmente entre 0,8 e 1,2; Tabela 5), feições estas coincidentes com as reconhecidas nos típicos TTG arqueanos (Moyen \& Martin, 2012). Os granodioritos apresentam padrões de elementos terras raras muito similares aos dos trondhjemitos, mas com algumas amostras exibindo conteúdo de $\Sigma$ ETR levemente mais elevado e padrões de ETR pesados ligeiramente côncavos.

\section{CARACTERIZAÇÃO DA SÉRIE MAGMÁTICA}

Tanto os tonalitos/trondhjemitos quanto os granodioritos incidem no domínio cálcio-alcalino do triângulo AFM (Figura 9A) e possuem composições peraluminosas (Shand, 1950; Figura 9B). A discriminação geoquímica dos grupos petrográficos avaliados aparece claramente no diagrama An-Ab-Or normativo (Figura 9C), de O'Connor (1965), com campos redefinidos por Barker (1979). Os tonalitos/ trondhjemitos incidem exclusivamente no campo dos trondhjemitos pobres em $\mathrm{K}_{2} \mathrm{O}$, ao passo que os granodioritos estão distribuídos no campo dos trondhjemitos, com extensão para o campo dos granitos. No diagrama K-Na-Ca (Figura 9D), os trondhjemitos se situam no campo dos típicos TTG arqueanos (Moyen \& Martin, 2012), enquanto que os granodioritos, embora incidam parcialmente no mesmo 




Figura 7. Diagramas de Harker para os elementos-traço da associação TTG estudada, em comparação com as associações TTG da Província Carajás: A) Rb; B) Sr; C) Ba; D) Sr/Ba; E) Rb/Sr; F) Zr; G) Y; H) Yb. Fontes dos dados das suítes TTG: Domínio Rio Maria (Almeida et al., 2011); Trondhjemito Rio Verde (Feio et al., 2013); Trondhjemito Colorado (Silva et al., comunicação pessoal, 2013). 




Figura 8. A e C) Padrões de elementos terras raras da associação TTG do leste do Subdomínio de Transição, normalizados em relação ao condrito (Evensen et al., 1978); B e D) diagrama de multielementos normalizados em relação ao manto primitivo (Taylor \& McLennan, 1985).

campo, apresentam enriquecimento em potássio e sugerem uma assinatura geoquímica aparentemente de afinidade cálcio-alcalina, contrastante com a das típicas suítes TTG (Moyen \& Martin, 2012). O diagrama P-Q (Debon \& Le Fort, 1983; Figura 9E) distingue nitidamente as rochas analisadas de composições tonalíticas/trondhjemíticas ou granodioríticas. As rochas com composições modais de granodioritos incidem francamente no campo dessas rochas, enquanto as amostras que plotam próximo do limite entre os campos de tonalitos e granodioritos (PFR-1, PFR-10A, PFR-33A, PFR-40 e MYF-67) são as que apresentavam discordância entre a classificação petrográfica e geoquímica. Chegou-se à conclusão de que elas são realmente granodioritos, pois apresentam moderados conteúdos modais de microclina (Tabela 1), conteúdos de $\mathrm{K}_{2} \mathrm{O}$ superiores a 2\% (Tabela 5) e por se situarem no campo dos granodioritos, ou muito próximas a ele, no diagrama P-Q.
Apesar das similaridades observadas entre tonalitos/ trondhjemitos e granodioritos, é importante assinalar que, nos diagramas de Harker (Figuras 6 e 7), essas duas variedades de rochas não mostram trends compatíveis com vinculação por processos de diferenciação magmática. Isso é particularmente marcante nos casos dos álcalis e da grande maioria dos elementos-traço, merecendo destaque $\circ \mathrm{Rb}$ e sobretudo $\mathrm{Ba}$, que exibem teores comparativamente elevados nos granodioritos (Figuras 7A, 7C). Por outro lado, os baixos conteúdos de elementos ferromagnesianos, aliados aos valores moderados de \#Mg e aos padrões similares de ETR dos granodioritos e tonalitos/trondhjemitos (Figuras 8A, 8C), aproximam os granodioritos dos típicos TTG arqueanos. Isso é reforçado pelo que se observa no diagrama de multielementos (Figuras 8B, 8D), normalizado em relação à composição do manto primitivo (Taylor \& McLennan, 1985), no qual o conjunto de amostras apresenta

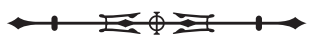



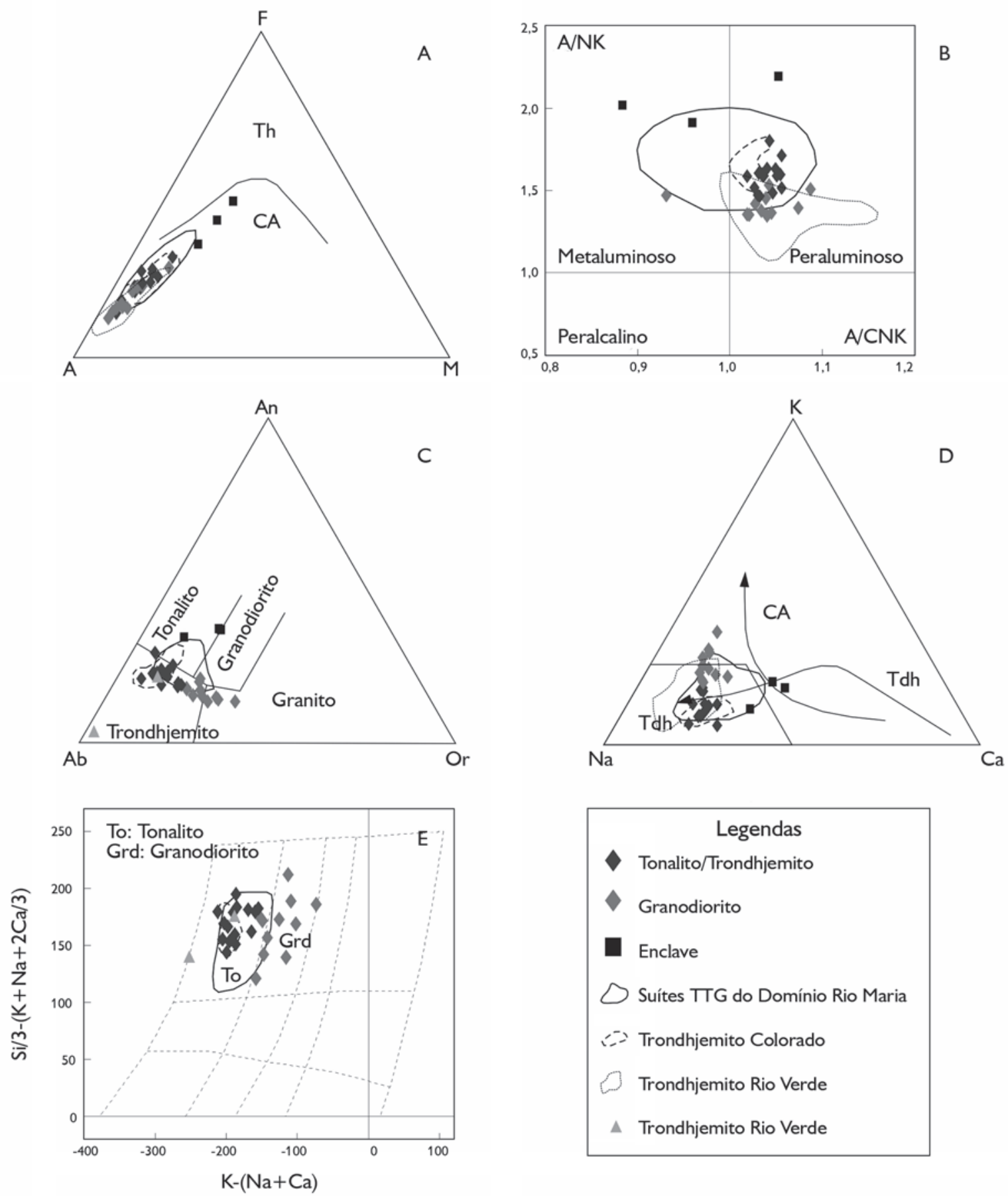

Figura 9. Caracterização geoquímica da associação TTG do leste do Subdomínio de Transição: A) Diagrama $A F M\left(A=N a_{2} O+K_{2} O ; F=\right.$ $\mathrm{FeO}+0,9 * \mathrm{Fe}_{2} \mathrm{O}_{3} ; \mathrm{M}=\mathrm{MgO}$; campos de Irvine \& Baragar, 1971); $\left.\mathrm{B}\right)$ diagrama $\left[\mathrm{Al}_{2} \mathrm{O}_{3} /\left(\mathrm{Na}_{2} \mathrm{O}+\mathrm{K}_{2} \mathrm{O}\right)\right] \mathrm{mol}$ versus $\left[\mathrm{Al}_{2} \mathrm{O}_{3} /\left(\mathrm{CaO}+\mathrm{Na}_{2} \mathrm{O}+\mathrm{K}_{2} \mathrm{O}\right)\right]$ mol (Maniar \& Piccoli, 1989); C) diagrama An-Ab-Or normativo (O'Connor, 1965, com campos de Barker, 1979); D) diagrama K-Na-Ca (trends CA = cálcio-alcalino e Tdh = trondhjemítico, segundo Barker \& Arth, 1976; campo Thd, conforme Martin, 1994); E) diagrama P-Q (Debon \& Le Fort, 1983).

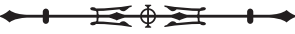


padrões muito similares, com acentuadas anomalias negativas de $\mathrm{Nb}$ e $\mathrm{P}$ e mais discreta de $\mathrm{Ti}$, coincidentes com os padrões das típicas associações TTG arqueanas (Moyen \& Martin, 2012), exceto pelo fato de os granodioritos exibirem anomalias positivas de $\mathrm{Ba}$. Os diagramas $\mathrm{P}-\mathrm{Q}$ e $\mathrm{K}-\mathrm{Na}-\mathrm{Ca}$ (Figuras 9E, 9D) fornecem, por sua vez, evidências de que os granodioritos evoluíram de forma independente.

Uma evidência adicional da afinidade dos tonalitos e trondhjemitos com as associações TTG é fornecida pela ausência de anomalias expressivas de Sr e Eu, assim como pelos valores de $\mathrm{Yb}(<1 \mathrm{ppm})$ e da razão $\mathrm{Sr} / \mathrm{Y}$ compreendidas em sua quase totalidade, com exceção dos enclaves, no intervalo entre 50 e 500 (Tabela 5), admitido como característico dos TTG (Moyen \& Martin, 2012). Conclui-se que o conjunto de tonalitos e trondhjemitos da área estudada apresenta todas as características das típicas associações TTG arqueanas (Martin, 1994; Almeida et al., 2011; Moyen \& Martin, 2012). Por outro lado, embora os granodioritos possuam afinidade com os tonalitos e trondhjemitos em termos de série magmática, muito provavelmente não derivaram diretamente do magma gerador dos mesmos por processos de diferenciação magmática, e sua origem necessita ser discutida.

\section{DISCUSSÃO}

\section{COMPARAÇÕES COM AS ASSOCIAÇÕES TTG DA} PROVÍNCIA CARAJÁS

A associação TTG do extremo leste do SDT é muito similar às associações TTG identificadas no Domínio Rio Maria e no Subdomínio de Transição. Em termos petrográficos, as rochas estudadas são formadas por tonalitos e trondhjemitos, com granodioritos subordinados, e contêm como principais minerais ferromagnesianos biotita e epidoto magmático, tal como observado em todas as suítes TTG da Província Carajás. Porém, a associação entre membros trondhjemíticos e granodioríticos identificada neste trabalho é rara, tendo sido identificada, apenas, no Trondhjemito Água Fria (Leite et al., 2004), do DRM. Almeida et al. (2011) mostraram que os
TTG de Rio Maria pertencem à série alto- $\mathrm{Al}_{2} \mathrm{O}_{3}$, possuem caráter cálcio-alcalino, plotam no campo médio-K, são pobres em ferromagnesianos $\left(\mathrm{Fe}_{2} \mathrm{O}_{3}+\mathrm{MnO}+\mathrm{MgO}+\mathrm{TiO}_{2}\right.$ $\leq 5 \%$ ), mostram valores de $\mathrm{A} / \mathrm{CNK}$ entre 0,9 e 1,1, têm razões $\mathrm{K}_{2} \mathrm{O} / \mathrm{Na}_{2} \mathrm{O}$ geralmente $<0,5$, moderado \#Mg, e possuem caráter sódico (diagrama K-Na-Ca, Barker \& Arth, 1976). Todas as características supracitadas são típicas de associações TTG (Martin, 1994; Moyen \& Martin, 2012) e se repetem, com poucas exceções, na associação TTG do Domínio Carajás, representada pelo Trondhjemito Rio Verde (Feio et al., 2013) e Trondhjemito Colorado (Silva et al., comunicação pessoal, 2013). A associação estudada neste trabalho também mostra equivalência geoquímica com as típicas suítes TTG arqueanas e exibe uma nítida afinidade com as demais suítes TTG já identificadas na Província Carajás.

Em uma comparação (Figura 10) com os grupos de TTG com alta, média e baixa razão La/Yb do Domínio Rio Maria (Almeida et al., 2011), os quais não apresentam correspondência direta com as diferentes suítes TTG descritas naquele domínio, verificou-se que as rochas estudadas exibem sobreposição com os grupos de altas e médias razões La/Yb e Sr/Y, com exceção dos enclaves, que possuem razão La/Yb baixa (Figura 10A). Por outro lado, as razões $\mathrm{Sr} / Y$ são quase sempre maiores que 50 e fazem com que as amostras dos TTG do leste do Subdomínio de Transição se concentrem no diagrama $\mathrm{Sr} / \mathrm{Y}$ versus La/Yb (Figura 10B) em um único campo. As comparações revelam que as rochas estudadas possuem maior afinidade geoquímica com as associações TTG do grupo com alto Sr e altas razões La/Yb e Sr/Y, representadas, principalmente, pelo Trondhjemito Mogno e Tonalito Mariazinha no Domínio Rio Maria (Almeida et al., 2011) e pelo Trondhjemito Colorado no Subdomínio de Transição (Silva et al., comunicação pessoal, 2013). Em comparação com o Trondhjemito Rio Verde (Feio et al., 2013), foi observada uma relação um pouco distinta, pois essa unidade apresenta rochas com razão La/Yb moderada a alta, as quais se dividem em subgrupos devido aos valores de $\mathrm{Sr} / \mathrm{Y}$ com variações acentuadas de médios a elevados. 
Em comparação com outras suítes TTG descritas na literatura internacional, destacando a associação TTG do Cráton Pilbara (Champion \& Smithies, 2007) e os grupos de TTG de alto e baixo Sr distinguidos por Moyen et al. (2007) no Terreno-granito-greenstone de Barberton, o diagrama Sr versus $\mathrm{SiO}_{2}$ (Figura 10C) revela que as rochas estudadas possuem afinidade com a associação de alto $\mathrm{Al}$ e alto $\mathrm{Sr}$ do Cráton Pilbara, que se superpõe parcialmente com o campo definido para o grupo de baixo Sr de Barberton.
Poucas amostras ocorrem no campo dos TTG com alto $\mathrm{Sr}$ de Barberton. Tal comportamento é similar ao observado para a maioria dos TTG do Domínio Rio Maria (Almeida et al., 2011) e para o Trondhjemito Colorado (Silva et al., comunicação pessoal, 2013).

O comportamento dos elementos terras raras (ETR), com acentuado fracionamento dos ETR pesados em relação aos leves e ausência de anomalias negativas de Eu, reforça as afinidades petrológicas verificadas entre

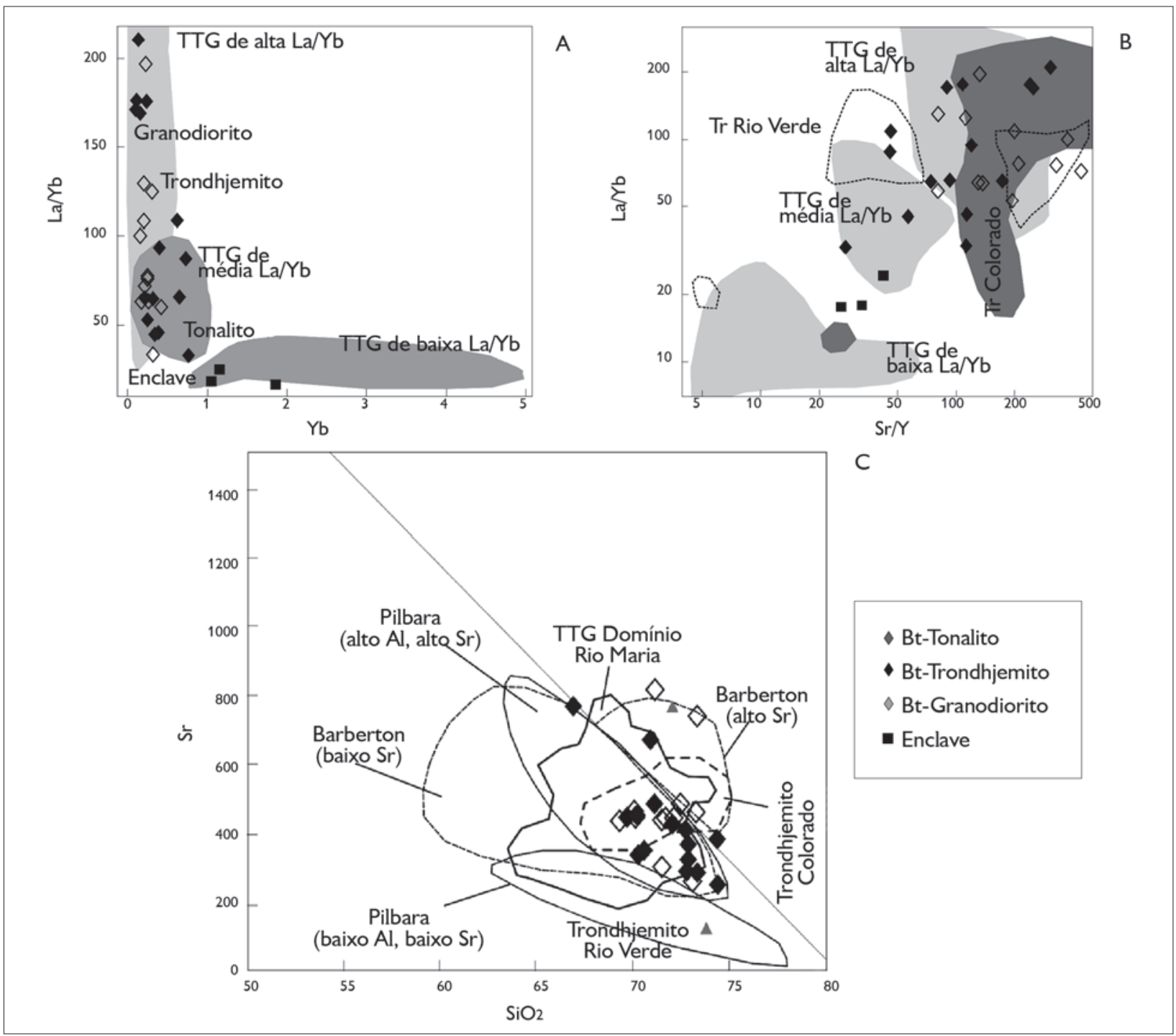

Figura 10. Diagramas geoquímicos comparando associações TTG do leste do Subdomínio de Transição com associações TTG da Província Carajás e de outros crátons arqueanos do mundo: A) Yb versus La/Yb; B) Sr/Y versus La/Yb; C) $\mathrm{SiO}_{2}$ versus Sr.

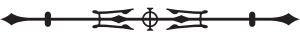


a associação TTG do leste do Subdomínio de Transição, o Trondhjemito Mogno e o Tonalito Mariazinha (Figuras 11A, 11C, 11E). Essa similaridade também se estende para o grupo de alta razão $(\mathrm{La} / \mathrm{Yb})_{N}$ e anomalias negativas de Eu pouco marcadas do Trondhjemito Colorado (Silva et al., comunicação pessoal, 2013), sendo importante destacar que não foram identificados, neste trabalho, padrões de ETR com anomalias positivas de Eu, tal como observado em algumas amostras deste último (Figuras 11D, 11F). No granodiorito (Figura 11B) se observa sobreposição com o grupo de média razão $(\mathrm{La} / \mathrm{Yb})_{N}$, e as tendências de concavidade observadas nos ETR pesados favorecem uma afinidade com certas amostras do Tonalito Mariazinha (Figura 11G) e com o Trondhiemito Rio Verde (Figura 11H).

\section{PROCESSOS DE FORMAÇÃO DOS GRANODIORITOS}

\section{Cristalização fracionada a partir do líquido residual do magma trondhjemítico}

A hipótese de que os granodioritos sejam os termos mais evoluídos da série trondhjemítica e de que os magmas formadores dessas rochas sejam ligados por diferenciação magmática resultante de processos de cristalização fracionada não é corroborada pelos dados geoquímicos, conforme discutido anteriormente. O conjunto de amostras dessas duas variedades mostra ampla superposição nos seus teores de sílica (69,31 a 73,4\% para tonalitos/trondhjemitos e $70,10 \%$ a $74,35 \%$ para os granodioritos), mas com ligeiro enriquecimento nas fases granodioríticas. Caso houvesse diferenciação magmática, ela deveria ter ocorrido sem aumento de sílica e com enriquecimento acentuado de $\mathrm{K}_{2} \mathrm{O}$ e Ba. Como, de modo geral, os conteúdos de $\mathrm{K}$ e Ba nos granodioritos tendem a ser pelo menos duas vezes mais elevados do que nos trondhjemitos, é altamente improvável que os primeiros possam ter sido gerados a partir dos magmas formadores desses trondhjemitos por diferenciação magmática. Outro fator que enfraquece a hipótese de diferenciação por cristalização fracionada é o fato de que magmas ricos em sílica não operam eficientemente o fracionamento de cristais.

Origem a partir da fusão parcial de crosta tonalíticotrondhjemítica

O fato de os granodioritos apresentarem comportamento distinto dos trondhjemitos no diagrama K-Na-Ca (Figura 9D) sugere que eles podem ter sido originados a partir de fontes (e/ou processos) diferentes. Modelos petrogenéticos indicam que os TTG são originados a partir de fusão parcial de fontes máficas, seja de crosta oceânica em ambientes de subducção (Martin, 1987), seja da base de pilhas espessas de sequências metavulcânicas (Bédard et al., 2003; Condie, 2005), ou ainda de fragmentos de crosta máfica que adentram o manto devido a processos de delaminação (Condie \& Abbott, 1999; Bédard, 2006), conforme discutido por Moyen \& Martin (2012) e Moyen \& Van Hunen (2012). Tais modelos certamente são adequados para explicar a formação dos magmas geradores dos tonalitos e trondhjemitos. A origem dos granodioritos poderia, por sua vez, estar relacionada a processos de anatexia, com baixos graus de fusão de crosta tonalítico-trondhjemítica, seguida de enriquecimento em LILE (Martin et al., 1997). Essa hipótese implicaria diferença de idade significativa entre as fontes e o magma granodiorítico, a qual não foi comprovada até o momento. Os dados geoquímicos obtidos permitem, porém, avaliar essa hipótese. Eles mostram que os granodioritos apresentam comportamento de ETR muito similar ao dos trondhjemitos, indicando que suas origens poderiam estar ligadas a fontes análogas ou mesmo idênticas. Além disso, a ausência de anomalias negativas acentuadas de Eu nos granodioritos não favorece tampouco aquela interpretação, uma vez que rochas derivadas de magmas resultantes da fusão parcial de fontes TTG em ambiente crustal deveriam apresentar anomalias negativas significativas de Eu, devido à elevada probabilidade de retenção de plagioclásio no resíduo da fusão. Conclui-se que esse modelo não é adequado para explicar a formação dos granodioritos estudados. 




Figura 11. Padrões de ETR da associação TTG do leste do Subdomínio de Transição (SDT; Figuras A-B), comparados com associações TTG da Província Carajás (Figuras C-H): A) trondhjemitos do SDT; B) granodioritos do SDT; C) Tonalito Mariazinha, com alta razão La/Yb;

D) Trondhjemito Colorado, com alta razão La/Yb e anomalia de Eu pouco pronunciada; E) Trondhjemito Mogno com alta razão La/Yb;

F) Trondhjemito Colorado, com anomalia positiva de Eu; G) Trondhjemito Mogno com razão La/Yb média; H) Trondhjemito Rio Verde.




Origem a partir da fusão de rochas máficas ou intermediárias ou de fontes híbridas

Certas características geoquímicas das suítes TTG arqueanas (fracionamento acentuado dos ETR e empobrecimento em ETR pesados; marcante anomalia negativa de $\mathrm{Nb}$; ausência de anomalias expressivas de Eu e Sr; baixos teores de Th e U) também são observadas nos granodioritos e podem ser explicadas pela fusão parcial de uma fonte anfibolítica ou granada-anfibolítica (Tarney \& Saunders, 1990; Moyen \& Stevens, 2006). Entretanto, os altos conteúdos de $\mathrm{K}_{2} \mathrm{O}, \mathrm{Rb}$ e Ba presentes nos granodioritos são inconsistentes com a derivação a partir de fontes máficas. Champion \& Smithies (2007) demonstraram que rochas ricas em LILE não podem ser produzidas por processos de cristalização fracionada ou pela fusão parcial de precursores basálticos. No entanto, os mesmos autores reportaram diferentes hipóteses para explicar o enriquecimento de LILE em magmas TTG, incluindo principalmente assimilação e contaminação crustal por sedimentos oriundos da crosta oceânica em subducção. Relataram também que rochas vulcânicas intermediárias associadas com greenstone-belts podem ser fontes potenciais para a derivação dos TTG enriquecidos em potássio, tais como os TTG transicionais do Cráton Pilbara. Moyen et al. (2007) assumiram uma hipótese similar para explicar a origem dos granitoides enriquecidos em potássio, associados com os TTG no terreno granitogreenstone de Barberton. Halla (2005) também argumenta que sedimentos em zonas de subducção podem desempenhar um papel importante na origem de magmas arqueanos. Almeida et al. (2010), estudando as suítes leucogranodioríticas do Domínio Rio Maria, propuseram um modelo alternativo para explicar a origem de seus magmas. Com base em modelamento geoquímico, esses autores sugerem que os leucogranodioritos são derivados da mistura em diferentes proporções entre um magma granítico evoluído, enriquecido em LILE, especificamente Ba e Sr, e líquidos trondhjemíticos. Feio \& Dall'Agnol (2012), por sua vez, assumiram uma fonte com composição de andesito basáltico para gerar os magmas dos granitos mesoarqueanos da área de Canaã dos Carajás na porção norte do Subdomínio de Transição.

Conclui-se que, a partir de fontes intermediárias, o modelo de derivação dos granodioritos não pode ser descartado, embora não tenha sido comprovado com os dados disponíveis.

\section{Geração dos granodioritos por processos metassomáticos afetando crosta TTG}

Lópezet al. (2005)argumentaram que magmas granodioríticos podem ser produzidos pela interação entre magmas máficos hidratados, derivados do manto (magmas sanukitoides) e crosta tonalítica. No seu modelo, líquidos derivados do manto, ricos em potássio, liberam $\mathrm{H}_{2} \mathrm{O}+\mathrm{K}_{2} \mathrm{O}$ para a crosta continental, proporcionando uma reciclagem dos tonalitos em granodioritos. Com a transferência desses elementos, juntamente com outros LILE (por exemplo, Rb e Ba), deveria haver enriquecimento em LILE na crosta tonalítica, resultando em rochas similares aos granodioritos, mas preservando algumas características geoquímicas dos TTG. Essa proposta é, em parte, fragilizada porque não há registros de magmas sanukitoides na área estudada, capazes de interagir com os TTG dominantes, embora os primeiros tenham sido identificados mais a oeste, ainda dentro do Subdomínio de Transição (Gabriel \& Oliveira, comunicação pessoal, 2013).

Outro mecanismo possivelmente envolvido na gênese dessas rochas é a modificação de componentes crustais a partir de metassomatismo litosférico. Os elementos LILE, por formarem íons de grande raio iônico e possuírem baixa carga iônica, têm maior facilidade de escapar das estruturas minerais (são elementos extremamente móveis em processos metassomáticos), concentrando-se nas fases fluidas, liberadas a partir da litosfera oceânica em subducção. Tais fluidos seriam teoricamente capazes de contaminar associações TTG recém-formadas. De acordo com Martin (2012), sistemas magmáticos envolvendo ascensão de diápiros são comumente acompanhados de fluidos à base de $\mathrm{CO}_{2}+\mathrm{H}_{2} \mathrm{O}$, resultantes da desgaseificação do manto. Esses fluidos seriam responsáveis pelo metassomatismo da




crosta e podem interferir nos processos magmáticos. As limitações inerentes a essa hipótese são a indefinição da composição exata do fluido original e a taxa de contaminação advinda do metassomatismo litosférico. Entretanto, estudos experimentais indicam que fluidos metassomáticos litosféricos podem remobilizar elementos como $\mathrm{K}, \mathrm{Na}, \mathrm{Al}$, $\mathrm{Si}$ e Fe a partir de uma diversidade de rochas, de modo que o protólito se torne álcali-metassomatizado e a fase transportada se assemelhe a um granito. Os elementos são seletivamente mobilizados. $\bigcirc$ Al é significativamente menos móvel que $\mathrm{Si}, \mathrm{Na}, \mathrm{K}$ e Ba $(\mathrm{K}>\mathrm{Ba}>\mathrm{Na}>\mathrm{Si}>$ $\mathrm{Al})$. A eficiência do sistema é proporcional ao aumento da temperatura e da pressão (Martin, 2012). Nessas condições, espera-se que a contaminação das rochas originais seja dominantemente 'granítica', proporcionando um enriquecimento em álcalis e LILE.

A formação dos granodioritos também pode estar associada a metassomatismo ligado a eventos de retrabalhamento crustal, envolvendo processos de deformação e milonitização. Nesse caso, os protolitos podem sofrer modificação na sua assembleia mineral constituinte, tal como a substituição de plagioclásio por K-feldspato.

Embora a hipótese de metassomatismo em larga escala seja difícil de admitir, considerando que os granodioritos ocorrem em pequeno volume, entremeados aos tonalitos/trondhjemitos, e não formam, na área estudada, corpos mapeáveis, a hipótese de sua geração a partir de metassomatismo dos tonalitos e trondhjemitos não pode ser afastada. Porém, são indispensáveis estudos de maior detalhe para testar essa hipótese de modo mais conclusivo. Como bem dito, o pequeno volume dos granodioritos enfraquece a possibilidade. É necessário pensar em processos eficazes na formação dessas rochas e contemporâneos à geração dos tonalitos/trondhjemitos.

\section{FONTES E PRESSÃO DE ORIGEM DOS MAGMAS TRONDHJEMÍTICOS}

O comportamento dos ETR nos trondhjemitos, com acentuado fracionamento dos ETR pesados em relação aos leves (e as altas razões La/Yb), remete a fontes do tipo granada anfibolitos, com o fracionamento (ou retenção no resíduo) de granada e, possivelmente, anfibólio, controlando a evolução magmática, tal como normalmente admitido para os TTG arqueanos (Martin, 1987; Champion \& Smithies, 2007; Almeida et al., 2011; Moyen \& Martin, 2012). Além disso, a ausência de anomalias negativas de Eu indica que não houve fracionamento expressivo de plagioclásio. Isso é evidenciado também pelas altas razões $\mathrm{Sr} / \mathrm{Y}$, que fornecem forte indício de que essas rochas foram geradas em altas pressões (ca. 1,5 GPa), fora do domínio de estabilidade do plagioclásio. Esse quadro é muito similar ao observado para o grupo de TTG com altas razões La/Yb do Domínio Rio Maria (Almeida et al., 2011) e para a associação com alto Al e alto Sr do Cráton Pilbara (Champion \& Smithies, 2007).

\section{CONCLUSÕES}

- O extremo leste do SDT é dominado por rochas trondhjemíticas, com granodioritos subordinados, intensamente deformadas, estruturadas, em geral, segundo direção NW-SE a E-W. Localmente, apresentam estruturas NE-SW, transpostas por cisalhamentos E-W. O quadro estrutural sugere a atuação de uma deformação compressiva, aliada a um componente de cisalhamento, com movimentação lateral esquerda (sinistral), resultando em esforços transpressivos, com estresse $(\delta 1)$ atuando principalmente na direção NE-SW;

- Os tonalitos e trondhjemitos exibem perfeita correspondência com as típicas suítes TTG do arqueano (Moyen \& Martin, 2012). Em contrapartida, os termos granodioríticos mostram enriquecimento em $\mathrm{K}_{2} \mathrm{O}, \mathrm{Rb}$ e, sobretudo, Ba, e tendem a se alinhar com as séries cálcio-alcalinas;

- Os tonalitos e trondhjemitos estudados possuem maior afinidade geoquímica com o Tonalito Mariazinha e o Trondhjemito Mogno do DRM, Trondhjemito Colorado da porção centro-sul do SDT e, em menor grau, com o Trondhjemito Rio Verde, da região de Canaã dos 
Carajás, porção norte do SDT, todos da Província Carajás, e com a associação TTG com alto Al e alto Sr do Cráton Pilbara;

- Os resultados obtidos demonstram a existência de uma expressiva associação TTG no extremo leste do SDT. Esse fato implica notável diferença entre essa porção do SDT e a área de Canaã dos Carajás, onde dominam granitos strictu sensu, e fortalece a hipótese de que o SDT represente uma extensão do Domínio Rio Maria, afetado por eventos de retrabalhamento crustal durante o Neoarqueano;

- Os dados geoquímicos obtidos não favorecem a formação dos granodioritos nem por diferenciação magmática a partir dos trondhjemitos, nem por fusão parcial de crosta TTG mais antiga. Já o modelo de derivação dos granodioritos a partir de fontes intermediárias não pode ser descartado, nem tampouco a hipótese de que a origem dos membros granodioríticos esteja relacionada à contaminação de magmas ou associações TTG por fluidos capazes de transportar componentes graníticos extraídos de crosta félsica (metassomatismo litosférico), ou à assimilação de sedimentos oriundos da crosta oceânica em subducção. $\bigcirc$ metassomatismo, se de fato efetivo, teria atuado na área estudada em pequena escala;

- Os tonalitos e trondhjemitos derivaram da fusão parcial de fontes do tipo granada anfibolitos, em altas pressões (ca. 1,5 $\mathrm{GPa}$ ), com granada e, possivelmente, anfibólio, sendo retidos como fases residuais. Não houve fracionamento expressivo de plagioclásio durante a evolução magmática.

\section{AGRADECIMENTOS}

Aos pesquisadores do Grupo de Pesquisa Petrologia de Granitoides, do Instituto de Geologia, da Universidade Federal do Pará (GPPG-IG-UFPA), pelo apoio nas diversas etapas deste trabalho; ao IG-UFPA, pelo suporte técnico; à Coordenação de Aperfeiçoamento de Pessoal de Nível Superior (CAPES) e Conselho Nacional de Desenvolvimento Científico e Tecnológico (CNPq), pela concessão de bolsas de estudo (Mestrado - UFPA - PAS, MFBT), doutorado (FVG) e produtividade em pesquisa
(RD). Este trabalho é uma contribuição ao projeto Instituto Nacional de Ciência e Tecnologia (INCT) de Geociências da Amazônia (GEOCIAM; CNPq/MCT/FAPESPA - Processo n 573733/2008-2) e ao Projeto IGCP-SIDA-599.

\section{REFERÊNCIAS}

ACMELABS, s.d. AcmeLabs ${ }^{\mathrm{TM}}$ : a bureau veritas group company. Disponívelem: <muw.acmelab.com>. Acessoem: 23 novembro 2012.

ALMEIDA, J. A. C., R. DALL'AGNOL, S. B. DIAS \& F. J. ALTHOFF, 2010. Origin of the Archean leucogranodiorite-granite suites: evidence from the Rio Maria terrane and implications for granite magmatism in the Archean. Lithos 120(3-4): 235-257.

ALMEIDA, J. A. C., R. DALL'AGNOL, M. A. OLIVEIRA, M. J. B. MACAMBIRA, M. M. PIMENTEL, O. T. RÄMÖ, F. V. GUIMARÃES \& A. A. S. LEITE, 2011. Zircon geochronology, geochemistry and origin of the TTG suites of the Rio Maria granite-greenstone terrane: implications for the growth of the Archean crust of the Carajás Province, Brazil. Precambrian Research 187(1-2): 201-221.

ALTHOFF, F. J., P. BARBEY \& A.-M. BOULLIER, 2000. 2.8-3.0 Ga plutonism and deformation in the SE Amazonian craton: the Archean granitoids of Marajoara (Carajás Mineral Province, Brazil). Precambrian Research 104(3-4): 187-206.

ANDERSON, J. L. \& D. R. SMITH, 1995. The effects of temperature and $\mathrm{fO}_{2}$ on the Al-in-hornblende barometer. American Mineralogist 80(5-6): 549-559.

AVELAR, V. G., J. M. LAFON, F. C. CORREIA JR. \& E. M. B. MACAMBIRA, 1999. O magmatismo arqueano da região de Tucumã - Província Mineral de Carajás: novos resultados geocronológicos. Revista Brasileira de Geociências 29(4): 453-460.

BARKER, F., 1979. Trondhjemites: definition, environment and hypotheses of origin. In: F. BARKER (Ed.): Trondhjemites, dacites and related rocks: 1-12. Elsevier, Amsterdam.

BARKER, F. \& J. G. ARTH, 1976. Generation of trondhjemitictonalitic liquids and Archaean bimodal trondhjemite-basalt suites. Geology 4(10): 596-600.

BARROS, C. E. M., A. S. SARDINHA, J. P. O. BARBOSA, M. J. B. MACAMBIRA, P. BARBEY \& A. M. BOULLIER, 2009. Structure, petrology, geochemistry and zircon $\mathrm{U} / \mathrm{Pb}$ and $\mathrm{Pb} / \mathrm{Pb}$ geochronology of the synkinematic Archean (2.7 Ga) A-type granites from the Carajás Metallogenic Province, northern Brazil. The Canadian Mineralogist 47(6): 1423-1440.

BÉDARD, J. H., 2006. A catalytic delamination-driven model for coupled genesis of Archaean crust and sub-continental lithospheric mantle. Geochimica et Cosmochimica Acta 70(5): $1188-1214$. 
BÉDARD, J. H., P. BROUILLETTE, L. MADORE \& A. BERCLAZ, 2003. Archaean cratonization and deformation in the northern Superior Province, Canada: an evaluation of plate tectonics versus vertical tectonic models. Precambrian Research 127: 61-87.

BOWDEN, P., R. A. BATCHELOR, B. W. CHAPELL, J. DIDIER \& J. LAMEYRE, 1984. Petrological, geochemical and source criteria for the classification of granitic rocks: a discussion. Physics of the Earth and Planetary Interiors 35(1-3): 1-11.

CHAMPION, D. C. \& R. H. SMITHIES, 2007. Geochemistry of paleoarchean granites of the east Pilbara Terrane, Pilbara Craton, Western Australia: implications for early Archean crustal growth. In: M. J. VAN KRANENDONK, R. H. SMITHIES \& V. C. BENNETT (Eds.): Earth's oldest rocks: 369-410. Elsevier (Developments in Precambrian Geology, 15), Amsterdam.

CONDIE, K. C., 2005. TTGs and adakites: are they both slab melts? Lithos 80(1-4): 33-44.

CONDIE, K. C. \& D. H. ABBOTT (Eds.), 1999. Preface to special volume on Oceanic plateaus and hotspot islands: identification and role in continental growth. Lithos 46(1): 1-4.

DALL'AGNOL, R., M. A. OLIVEIRA, J. A. C. ALMEIDA, F. J. ALTHOFF, A. A. S. LEITE, D. C. OLIVEIRA \& C. E. M. BARROS, 2006. Archean and Paleoproterozoic granitoids of the Carajás metallogenetic province, eastern Amazonian Craton. Abstracts of Symposium on Magmatism, Crustal Evolution, and Metallogenesis of the Amazonian Craton 1: 97-150.

DEBON, F. \& P. LE FORT, 1983. A chemical-mineralogical classification of common plutonic rocks and associations. Transactions of the Royal Society of Edinburgh: Earth Sciences 73(3): 135-149.

EVENSEN, N. M., P. T. HAMILTON \& R. K. O'NIONS, 1978. Rare earth abundances in chondritic meteorites. Geochimica et Cosmochimica Acta 42(8): 1199-1212.

FEIO, G. R. L. \& R. DALL'AGNOL, 2012. Geochemistry and petrogenesis of the granites from the Canaã dos Carajás area, Carajás province, Brazil: implications for the origin of Archean granites. Lithos 154: 33-52.

FEIO, G. R. L., R. DALL'AGNOL, E. L. DANTAS, M. I. B. MACAMBIRA, A. C. B. GOMES, A. S. SARDINHA, D. C. OlIVEIRA, R. D. SANTOS \& P. A. SANTOS, 2012. Geochemistry, geochronology, and origin of the Neoarchean Planalto Granite suite, Carajás, Amazonian craton: A-type or hydrated charnockitic granites? Lithos 151: 57-73.

FEIO, G. R. L., R. DALL'AGNOL, E. L. DANTAS, M. J. B. MACAMBIRA, J. O. S. SANTOS, F. J. ALTHOFF \& J. E. B SOARES, 2013. Archean granitoid magmatism in the Canaã dos Carajás area: implications for crustal evolution of the Carajás province, Amazonian craton, Brazil. Precambrian Research 227: 157-185.

FOSTER, M. D., 1960. Interpretation of the composition of trioctahedral micas. United States Geological Survey Professional Paper 354B: 1-49
GALARZA, M. A., D. C. OLIVEIRA, R. D. SANTOS, A. C. MARTINS, A. N. SANTOS \& P. J. L. SANTOS, 2012. Geocronologia do diopsídionorito Pium e granitóides associados, Canaã dos Carajás, Província Carajás. Anais do Congresso Brasileiro de Geologia 46: 1 CD-ROM.

GOMES, A. C. B. \& R. DALL'AGNOL, 2007. Nova associação tonalítica-trondhjemítica neoarqueana na região de Canaã dos Carajás: TTGs com altos conteúdos de Ti, Zr e Y. Revista Brasileira de Geociências 37(1): 182-193.

GUiMARÃES, F. V., R. DALL'AGNOL, J. A. C. ALMEIDA \& M. A. OLIVEIRA, 2010. Caracterização geológica, petrográfica e geoquímica do Trondhjemito Mogno e Tonalito Mariazinha, Terreno Granito-Greenstone de Rio Maria, SE do Pará. Revista Brasileira de Geociências 40(2): 196-211.

HALLA, J., 2005. Late Archean high-Mg granitoids (sanukitoids) in the Southern Karelian craton, Eastern Finland. Lithos 79: 161-178.

HIRATA, W. K., J. C. RIGON, A. A. C. CORDEIRO \& E. M. MEIRELES, 1982. Geologia regional da Província Mineral de Carajás. Anais do Simpósio de Geologia da Amazônia 1: 100-110.

HUHN, S. B., M. J. B. MACAMBIRA \& R. DALL'AGNOL, 1999. Geologia e geocronologia Pb-Pb do Granito Alcalino Arqueano Planalto, Região da Serra do Rabo, Carajás - PA. Anais do Simpósio de Geologia da Amazônia 6(1): 463-466.

IRVINE, T. N. \& W. R. A. BARAGAR, 1971. A guide to the chemical classification of the common volcanic rocks. Canadian Journal of the Earth Sciences 8(5): 523-548.

KRETZ, R., 1983. Symbols for rock-forming minerals. American Mineralogist 68: 277-279.

LAFON, J. M., M. J. B. MACAMBIRA \& R. T. PIDGEON, 2000. Zircon U-Pb SHRIMP dating of Neoarchean magmatism in the southwestern part of the Carajás Province (eastern Amazonian Craton, Brazil). Abstracts of the International Geological Congress 31: 1 CD-ROM.

LAMEYRE, J. \& P. BOWDEN, 1982. Plutonic rock type series: discrimination of various granitoid series and related rocks. Journal of Volcanology and Geothermal Research 14(1-2): 169-186.

LE MAITRE, R. W. (Ed.), 2002. Igneous rocks: a classification and glossary of terms: 1-193. Cambridge University Press, London.

LEITE, A. A. S. \& R. DALL'AGNOL, 1997. Geologia e petrografia do maciço granítico Arqueano Xinguara e de suas encaixantes SE do Pará. Boletim do Museu Paraense Emílio Goeldi, série Ciências da Terra 9: 43-81.

LEITE, A. A. S., R. DALL'AGNOL, M. J. B. MACAMBIRA \& F. J. ALTHOFF, 2004. Geologia e geocronologia dos granitóides arqueanos da região de Xinguara-PA e suas implicações na evolução do terreno granito-greenstone de Rio Maria, Cráton Amazônico. Revista Brasileira de Geociências 34(4): 447-458.

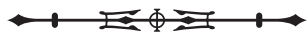


LÓPEZ, S., A. CASTRO \& A. GARCÍA-CASCO, 2005. Production of granodiorite melt by interaction between hydrous mafic magma and tonalitic crust. Experimental constraints and implications for the generation of Archaean TTG complexes. Lithos 79(1-2): 229-250.

MACAMBIRA, E. M. B. \& A. G. VALE, 1997. Programa Levantamentos Geológicos Básicos do Brasil. São Felix do Xingu. Folha SB.22-Y-B. Estado do Pará: 1-384. DNPM/CPRM, Brasília.

MACAMBIRA, M. J. B. \& J. M. LAFON, 1995. Geocronologia da Província Mineral de Carajás: síntese dos dados e novos desafios. Boletim do Museu Paraense Emílio Goeldi, série Ciências da Terra 7: 263-288.

MACHADO, N., Z. LINDENMAYER, T. E. KROGH \& D. LINDENMAYER, 1991. U-Pb geochronology of Archean magmatism and basement reactivation in the Carajás area, Amazon shield, Brazil. Precambrian Research 49(3-4): 329-354.

MANIAR, P. D. \& P. M. PICCOLI, 1989. Tectonic discrimination of granitoids. The Geological Society of America Bulletin 101(5): 635-643.

MARTIN, H., 1987. Petrogenesis of Archaean trondhjemites, tonalites, and granodiorites from eastern Filand: major and trace element geochemistry. Journal of Petrology 28(5): 921-953.

MARTIN, H., 1994. The Archean grey gneisses and the gneisses of continental crust. In: K. C. CONDIE (Ed.): Archean crustal evolution: 205-259. Elsevier (Developments in Precambrian Geology, 11), Amsterdam.

MARTIN, H., J. J. PEUCAT, J. C. SABATÉ\& \&. C. CUNHA, 1997. Crustal evolution in the early Archaean of South America: example of the Sete Voltas Massif, Bahia State, Brazil. Precambrian Research 82(1-2): 35-62.

MARTIN, R. F., 2012. The petrogenesis of anorogenic felsic magmas and AMCG suites: insights on element mobility and mutual cryptic contamination from polythermal experiments. Lithos 151: 35-45.

MORETO, C. P. N., L. V. S. MONTEIRO, R. P. XAVIER, W. S. AMARAL, T. J. S. SANTOS, C. JULIANI \& C. R. SOUZA FILHO, 2011. Mesoarchean (3.0 and $2.86 \mathrm{Ga}$ ) host rocks of the iron oxide-Cu-Au Bacaba deposit, Carajás Mineral Province: U-Pb geochronology and metallogenetic implications. Mineralium Deposita 46(7): 789-811.

MOYEN, J. F. \& G. STEVENS, 2006. Experimental constraints on TTG petrogenesis: implications for Archean geodynamics. In: K. BENN, J.-C. MARESCHAL \& K. C. CONDIE (Eds.): Archean geodynamics and environments: 149-178. American Geophysical Union, Washington.

MOYEN, J. F., G. STEVENS, A. F. M. KISTERS \& R. W. BELCHER, 2007. TTG plutons of the Barberton granitoid-greenstone terrain, South Africa. In: M. J. VAN KRANENDONK, R. H. SMITHIES \& V. C. BENNET (Eds.): Earth's oldest rocks: 607-668. Elsevier (Developments in Precambrian Geology, 11), Amsterdam.
MOYEN, J. F. \& H. MARTIN, 2012. Forty years of TTG research. Lithos 148: 312-336.

MOYEN, J. F. \& J. VAN HUNEN, 2012. Short-term episodicity of Archaean plate tectonics. Geology 40(5): 451-454.

NACHIT, H., N. RAZAFIMAHEFA, J. M. STUSSI \& J. P. CARRON, 1985. Composition chimique des biotites et typologie magmatique des granitoïdes. Comptes Rendus de l'Académie des Sciences 301(2): 813-818.

NACHIT, H., A. IBHI, E. H. ABIA \& M. B. OHOUD, 2005. Discrimination between primary magmatic biotites, reequilibrated biotites and neoformed biotites. Comptes Rendus Geoscience 337(16): 1415-1420.

O'CONNOR, J. T., 1965. A classification for quartz-rich igneous rocks based on feldspar ratios. United States Geological Survey Professional Paper 525B: 79-84.

OLIVEIRA, D. C., P. J. L. SANTOS, E. O. GABRIEL, D. S. RODRIGUES, A. C. FARESIN, M. L. T. SILVA, S. D. SOUSA, R. V. SANTOS, A. C. SILVA, M. C. SOUZA, R. D. SANTOS \& M. J. B. MACAMBIRA, 2010. Aspectos geológicos e geocronológicos das rochas magmáticas e metamórficas da região entre os municípios de Água Azul do Norte e Canaã dos Carajás - Província Mineral de Carajás. Anais do Congresso Brasileiro de Geologia 45: 1 CD-ROM.

OLIVEIRA, M. A., R. DALL'AGNOL, F. J. ALTHOFF \&A. A. S. LEITE, 2009. Mesoarchean sanukitoid rocks of the Rio Maria GraniteGreenstone Terrane, Amazonian craton, Brazil. Journal of South American Earth Sciences 27(2-3): 146-160.

OLIVEIRA, M. A., R. DALL'AGNOL \& B. SCAILLET, 2010. Petrological constraints on crystallization conditions of Mesoarchean Sanukitoid Rocks, southeastern Amazonian Craton, Brazil. Journal of Petrology 51(10): 2121-2148.

PIDGEON, R. T., M. J. B. MACAMBIRA \& J. M. LAFON, 2000. Th- $U-P b$ isotopic systems and internal structures of complex zircons from an enderbite from the Pium Complex, Carajás Province, Brazil: evidence for the ages of granulites facies metamorphism and the protolith of the enderbite. Chemical Geology 166(1-2): 159-171.

PIMENTEL, M. M. \& N. MACHADO, 1994. Geocronologia U-Pb dos terrenos granito-greenstone de Rio Maria, Pará. Boletim de Resumos Expandidos do Congresso Brasileiro de Geologia 38(2): 390-391.

RICCI, P. S. F. \& M. A. CARVALHO, 2006. Rocks of the PiumArea, Carajás Block, Brazil - A deep seated high-T gabbroic pluton (charnockitoid-like) with xenoliths of enderbitic gneisses dated at $3002 \mathrm{Ma}$ - The basement problem revisited. Boletim de Resumos Expandidos do Simpósio de Geologia da Amazônia 8: 1 CD-ROM.

SANTOS, R. D., D. C. OLIVEIRA \& R. M. K. BORGES, 2008. Geologia e petrografia das rochas máficas e ultramáficas do complexo Pium - Província Mineral de Carajás. Anais do Congresso Brasileiro de Geologia 44: 1-535.

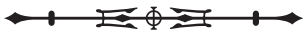


SARDINHA, A. S., R. DALL'AGNOL, A. C. B. GOMES, M. J. B. MACAMBIRA \& M. A. GALARZA, 2004. Geocronologia Pb-Pb e U-Pb em zircão de granitóides arqueanos da região de Canaã dos Carajás, Província Mineral de Carajás. Anais do Congresso Brasileiro de Geologia 42: 1 CD-ROM.

SARDINHA, A. S., C. E. M. BARROS \& R. KRYMSKY, 2006. Geology, geochemistry, and U-Pb geochronology of the Archean (2.74 Ga) Serra do Rabo granite stocks, Carajás Metallogenetic Province, northern Brazil. Journal of South American Earth Sciences 20(4): 327-339.

SHAND, S. J., 1950. Eruptive rocks, their genesis, composition, classification and their relation to ore deposits: 1-488. Thomas Murby, London.

SILVA, A. C., D. C. OliVEIRA \& M. J. B. MACAMBIRA, 2010. Individualização e geocronologia de granitóides do Complexo Xingu, região de Vila Jussara, município de Água Azul do Norte PA, Província Mineral de Carajás. Anais do Congresso Brasileiro de Geologia 45: 1 CD-ROM.

SILVA, G. G., M. I. C. LIMA, A. R. F. ANDRADE, R. S. ISSLER \& G. GUIMARÃES, 1974. Geologia. In: BRASIL. Projeto RADAMBRASIL: Folha SB.22 Araguaia e parte de SC.22 Tocantins; geologia, geomorfologia, pedologia, vegetação e uso potencial da Terra: 1: 1-143. Programa de Integração Nacional (Levantamento de Recursos Naturais, 4), Rio de Janeiro.

STRECKEISEN, A., 1976. To each plutonic rock its proper name. Earth Science Reviews 12(1): 1-33.

TARNEY, J. \& A. SAUNDERS, 1990. Crustal growth mechanisms and mantle evolution. Extended Abstracts of the International Archaean Symposium 3: 451-452.

TASSINARI, C. C. G \& M. J. B. MACAMBIRA, 2004. Evolução tectônica do Cráton Amazônico. In: V. MANTESSO-NETO, A. BARTORELLI, C. D. R. CARNEIRO \& B. B. BRITO NEVES (Orgs.): Geologia do continente sul americano: evolução da obra de Fernando Flávio Marques de Almeida: 471-486. BECA, São Paulo.
TAYLOR, S. R. \& S. M. MCLENNAN, 1985. The continental crust: its composition and evolution: 1-321. Blackwell Scientific, Oxford.

TEIXEIRA, M. F. B., R. DALL'AGNOL, A. C. SILVA \& P. A. SANTOS, 2013. Geologia, petrografia e geoquímica do Leucogranodiorito Pantanal e dos leucogranitos arqueanos da área a norte de Sapucaia, Província Carajás, Pará: implicações petrogenéticas. Boletim do Museu Paraense Emílio Goeldi. Ciências Naturais 8(3): 291-323.

TULLOCH, A. J., 1979. Secondary Ca-Al silicates as low-grade alteration products of granitoid biotite. Contributions to Mineralogy and Petrology 69(2): 105-117.

VANCE, J. A., 1969. On synneusis. Contributions to Mineralogy and Petrology 24: 7-29.

VASQUEZ, M. L., L. R. ROSA-COSTA, C. G. SILVA, P. F. RICCI, J. O. BARBOSA, E. L. KLEIN, E. S. LOPES, E. B. MACAMBIRA, C. L. CHAVES, J. M. CARVALHO, J. G. OLIVEIRA, G. C. ANJOS \& H. R. SILVA, 2008a. Geologia e recursos minerais do estado do Pará: Sistema de Informações Geográficas - SIG: texto explicativo dos mapas geológico e tectônico e de recursos minerais do estado do Pará. In: M. L. VASQUES \& L. T. ROSA-COSTA (Orgs.): Escala 1:1.000.000: 118-121. CPRM, Belém.

VASQUEZ, M. L., M. J. B. MACAMBIRA \& R. A. ARMSTRONG, 2008b. Zircon geochronology of granitoids from the western Bacajá domain, southeastern Amazonian craton, Brazil: Neoarchean to Orosirian evolution. Precambrian Research 161(3-4): 279-302.

WHITNEY, D. L. \& B. W. EVANS, 2010. Abbreviations for names of rock-forming minerals. American Mineralogist 95: 185-187.

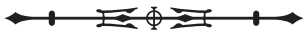

